\title{
High-Resolution Regional Climate Simulations over Iceland Using Polar MM5*
}

\author{
DAVID H. BROMWICH \\ Polar Meteorology Group, Byrd Polar Research Center, and Atmospheric Sciences Program, Department of Geography, \\ The Ohio State University, Columbus, Ohio \\ LESHENG BAI \\ Polar Meteorology Group, Byrd Polar Research Center, The Ohio State University, Columbus, Ohio \\ GUDMUNDUR G. BJARNASON ${ }^{+}$ \\ Office of Environmental Protection, Environmental and Food Agency, Reykjavik, Iceland
}

(Manuscript received 9 August 2004, in final form 23 June 2005)

\begin{abstract}
High-resolution regional climate simulations of Iceland for 1991-2000 have been performed using the fifth-generation Pennsylvania State University-National Center for Atmospheric Research (PSU-NCAR) Mesocale Model (MM5) modified for use in polar regions (Polar MM5) with three nested domains and short-duration integrations. The simulated results are compared with monthly mean surface observations from Iceland for 1991-2000 to demonstrate the high level of model performance; correlation coefficients exceed 0.9 for most variables considered.

The simulation results are used to analyze the near-surface climate over Iceland. The simulated nearsurface winds in winter are primarily katabatic. The land-sea-breeze circulation is clearly evident in summer. The land is colder than the ocean during winter, with a strong (weak) temperature gradient along the southern (northern) coast. This temperature pattern over the sloping terrain forces the katabatic wind. The diurnal cycle of near-surface air temperature is marked in summer over the land areas, which drives the land-sea breeze. The near-surface climate variations for extremes of the North Atlantic Oscillation (NAO) index during winter and summer result from the large-scale atmospheric advection conditions.

The time-averaged mesoscale precipitation distribution over Iceland is reasonably well simulated by Polar MM5. Winter precipitation rates are double those during the summer, reflecting the much greater winter cyclonic activity. The simulated interannual precipitation variations during winter for 1991-2000 agree with those observed from snow accumulation measurements on the Vatnajökull ice cap. The winter precipitation decrease for 1991-2000 dominates the annual signal for all of Iceland except the northeastern and eastern parts where the precipitation increases. The large precipitation trends (decadal decrease of up to $50 \%$ ) are caused by the eastward shift and weakening of the Icelandic low during the 1990 s, as a result of changes in the NAO modulation of regional climate.
\end{abstract}

\section{Introduction}

Iceland is a high-latitude island that contains a variety of microclimates because of its complex mesoscale

* Byrd Polar Research Center Contribution Number 1241.

+ Deceased.

Corresponding author address: David H. Bromwich, Polar Meteorology Group, Byrd Polar Research Center, The Ohio State University, 1090 Carmack Rd., Columbus, OH 43210.

E-mail: bromwich@polarmet1.mps.ohio-state.edu terrain and land use (e.g., Einarsson 1984). The local or regional climate can be analyzed by using observations but descriptions are incomplete because the observations are concentrated at low elevations. In particular it is difficult or impossible to analyze the wind fields and precipitation forced by terrain using only observational data. Two alternative modeling approaches can be used to reconstruct regional historical climate. One is regional reanalysis in which a state-of-the-art data assimilation system is used to reprocess all past environmental observations by combining them with short-term forecasts that are driven by global reanalysis at the lateral boundaries (such as North American Regional Re- 
analysis; more information available online at http:// www.emc.ncep.noaa.gov/mmb/rreanl/). A best estimate of the state and evolution of the environment is derived and estimates of a host of difficult to observe quantities such as latent heating, surface fluxes, and vertical motion, are provided. However, regional reanalysis is too complicated and computationally demanding to use for most regional climate applications. The other approach is regional climate simulation using a regional climate model or weather forecasting model in a limited area where the horizontal resolution typical for the mesoscale is applied to a small region of interest.

Regional climate simulations, based on the concept of "dynamic downscaling" and implying that regional climate is conditioned but not completely determined by the larger-scale state, consistently improve the spatial and temporal detail of simulated climate compared to global climate models (GCMs; Rinke et al. 1999a,b; Rinke and Dethloff 2000). They show promise in being able to reproduce the regional detail in surface climate as forced by topography, lakes, coastlines, and variations in land surface type. A global model provides the lateral boundary conditions for the regional climate model. However, the difference in horizontal resolution between the global and regional models (a factor of $\sim 5$ ) needs to be addressed with respect to the treatment at the lateral boundaries (von Storch et al. 2000).

Several approaches are generally used to simulate regional climate. One is long-period simulations that have the advantage of keeping the long-term forcing uninterrupted, but the model atmosphere in the domain interior may drift from the observations because of model limitations such as inaccurate numerics and errors in physical parameterizations. A long-period simulation is often used for climate sensitivity studies to investigate the regional response to particular forcings. A sequence of short integrations can minimize possible drift caused by accumulated model errors but the spinup problems introduced by the reinitializations must be addressed. Pan et al. (1999) evaluated the two approaches and found that the locations of specific meteorological features drifted downstream because simulated winds were too strong during long-term integration and that the simulation results can be improved by a sequence of short-segment integrations. By using the second version of the regional climate model (RegCM2), Qian et al. (2003) compared long-term continuous integration with consecutive medium-and short-term reinitialized simulations to study their relative performance and error growth. By comparing simulated and observed precipitation, they found that 10-day reinitialized runs result in the smallest error among the three simulation approaches. The results suggest the use of 10-day reinitialized runs for downscaling average conditions, that is, a sequence of 12-day reinitialized runs, with the output of the first 2 days discarded for spinup reasons. However, this approach is not applied here because we are interested in variability on daily time scales.

Another regional climate simulation method is dynamical downscaling using short-segment integrations, which applies a numerical weather prediction model to hindcast regional or local atmospheric states from global analysis data. With this method the atmospheric behavior is determined not only by the model physical processes along with regional terrain and land use but also by the initial conditions. The short segments are generally less than $72 \mathrm{~h}$ with $6 \sim 24$-h spinup time. Because of the short integration time, the effects of lateral boundary errors are minimized. Regional climate simulation studies of the Greenland area using this method obtained skillful results (Bromwich et al. 2001; Cassano et al. 2001; Box et al. 2004) in part because the largescale flow in the mid- and upper troposphere is across the integration domain. Olafur and Olafsson (2002) did experiments with the standard fifth-generation Pennsylvania State University-National Center for Atmospheric Research (PSU-NCAR) Mesocale Model (MM5; discussed in section 2a) to determine the optimal configuration for climatological downscaling studies of precipitation over Iceland. They found that the precipitation is reasonably simulated by MM5 and the simulation results are not sensitive to domain size or vertical resolution. The simulations also display only modest sensitivity to the planetary boundary layer and microphysics parameterizations. Increased model horizontal resolution yields a slightly more detailed precipitation pattern and higher maximum values. It is concluded that simulations of Iceland precipitation are insensitive to the precise modeling approach.

In this study, to limit the systematic bias of the regional model, a short-time integration dynamical downscaling method is adopted to hindcast high-resolution regional climate over Iceland for 1991-2000 from Polar MM5 (see below). The model is described in section 2. Evaluation of the regional simulation over Iceland is presented in section 3, and the simulation results are shown in section 4 . Section 5 summarizes the main conclusions.

\section{Model description}

\section{a. Polar MM5 dynamics and physics}

The MM5 model (Grell et al. 1994) has been modified for use in polar regions by the Polar Meteorology Group of the Byrd Polar Research Center at The Ohio 
State University and is referred to as the Polar MM5. The Polar MM5 model used here is based on version 3.5 of the PSU-NCAR MM5. A detailed discussion of the modifications made to the standard version of MM5 for use over polar regions is described in Bromwich et al. (2001) and Cassano et al. (2001). The key modifications are the following: revised cloud-radiation interaction, modified explicit ice phase microphysics, optimal turbulence (boundary layer) parameterization, implementation of a sea ice surface type, and improved treatment of heat transfer through snow/ice surfaces.

A sixth-order finite-difference scheme ( $\mathrm{Chu}$ and Fan 1997) is implemented here to calculate the horizontal pressure gradient force more accurately to reduce the computational error and improve the simulation over the steep topography of Iceland.

Model validations and case studies of Polar MM5 simulations over Greenland and Antarctica have been performed, and the model is currently being used for synoptic and climate studies in the data-sparse high latitudes. Cassano et al. (2001) simulated a complete annual cycle over the Greenland ice sheet using Polar MM5, and the results showed a high degree of forecast skill for all variables when verified with automatic weather station (AWS) data. Bromwich et al. (2001) simulated katabatic winds over Greenland with the Polar MM5. In addition to realistic performance against AWS observations, comparisons of the modeled profiles of wind speed, wind direction, and potential temperature in the katabatic layer with aircraft observations are also favorable, with small mean errors. Box et al. (2004) used the same simulations as presented here to investigate the surface mass balance over the Greenland ice sheet. The monthly mean state variables were well captured in relation to AWS observations for 1998-2000. In view of the reliable performance of Polar MM5 over Greenland, it is inferred that the model should perform with similar skill for Iceland.

\section{b. Modeling approach}

The nonhydrostatic Polar MM5 with 8-km resolution has been applied to simulate the regional climate over Iceland using forcing at the lateral boundaries from the European Centre for Medium-Range Weather Forecasts (ECMWF) Tropical Ocean Global Atmosphere (TOGA) operational analyses. Three nested model domains (Fig. 1a) are used to get reasonable lateral boundary conditions from the global analyses for the mesoscale simulation. The horizontal resolution and grid points are $72 \mathrm{~km}, 85 \times 73$ for domain $1 ; 24 \mathrm{~km}, 108$ $\times 121$ for domain 2 ; and $8 \mathrm{~km}, 85 \times 73$ for domain 3 . The vertical discretization consists of 28 irregularly spaced $\sigma$ levels. Two upper boundary conditions can be
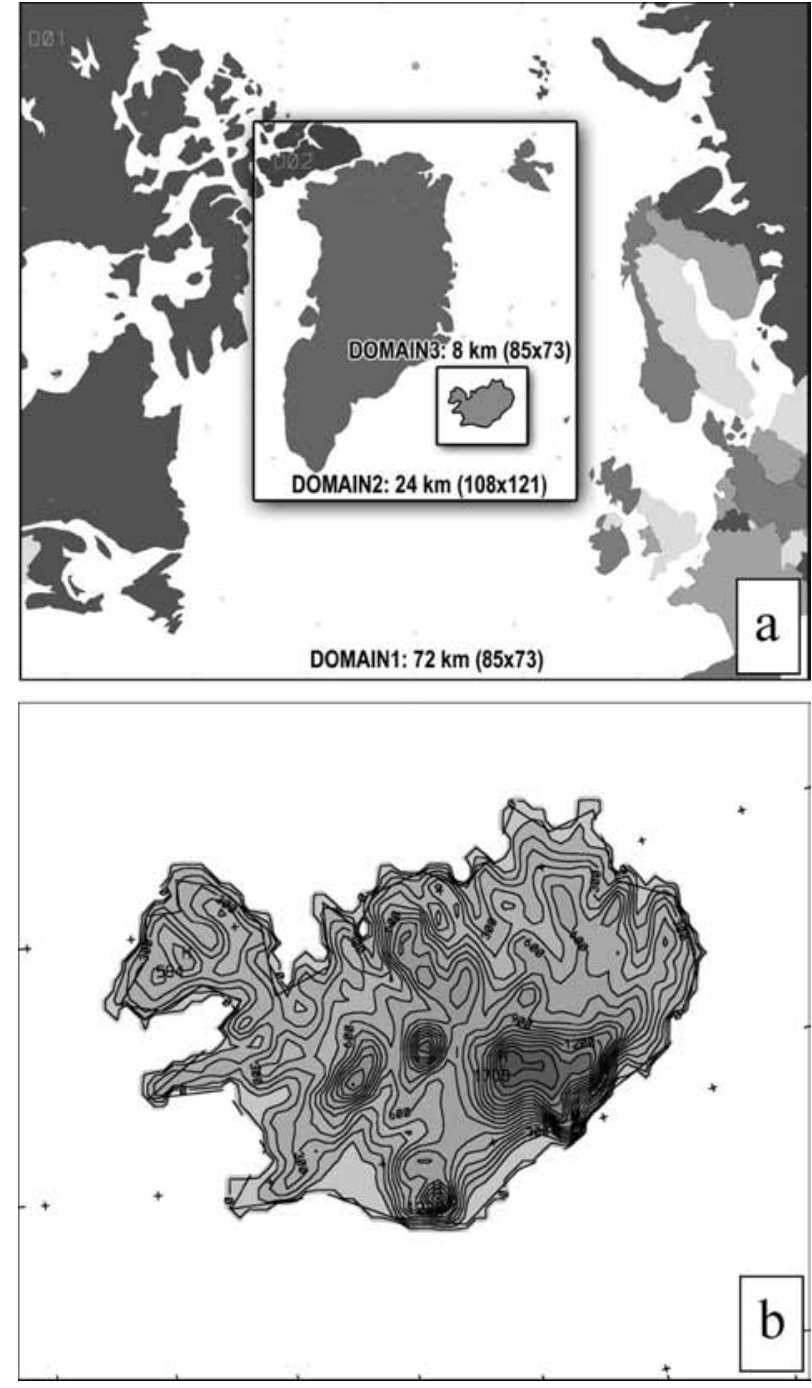

FIG. 1. (a) The model domains and (b) terrain of Iceland (8-km resolution); elevation contour interval is $100 \mathrm{~m}$.

chosen for Polar MM5: the rigid lid and radiative condition. The rigid-lid upper boundary condition is simple, and can filter out fast-traveling waves such as external gravity waves or acoustic waves, but has the disadvantage of reflecting upward-propagating waves downward back into the model domain. For many simulations, this is not a significant problem, but for some cases, such as commonly performed simulations of flow over a barrier, the rigid lid can distort the results. Wei et al. (2002) found that both upper boundary conditions did not work well for Antarctica where similar conditions of strong Coriolis forcing and steep terrain are present, and simulations can be improved for the rigid-lid upper boundary condition by raising the model top. The radiative condition is derived for pure hydrostatic gravity waves (ignoring the Coriolis forc- 
ing); the assumption may not be valid over Greenland, where the waves that propagate upward are strong due to Coriolis forcing as well as steep topography. For this reason, the model top is set at $10 \mathrm{hPa}$ and the rigid-lid upper boundary condition is used.

The model physics options for the three domains are the following: mixed phase explicit moisture scheme (Reisner et al. 1998); Grell cumulus scheme; the Community Climate Model version 2 (CCM2) atmospheric radiation scheme; and the medium-range forecast model (MRF) planetary boundary layer scheme. The $2.5^{\circ}$ horizontal resolution ECMWF TOGA surface and upper-air operational analyses are used to provide the initial and lateral boundary conditions for the model. The integration strategy for 1991-2000 is a sequence of 30 -h simulations, with the first $6 \mathrm{~h}$ being discarded for spinup reasons. Model output at 6-h intervals was saved for analysis. The $8-\mathrm{km}$ model terrain for Iceland is shown in Fig. $1 b$.

\section{c. Validation data}

The monthly climatic data for Iceland are from a monthly publication of the Icelandic Meteorology Office (IMO; more information available online at http:// www.vedur.is/vedurfar/yfirlit/vedurfarsgogn_en.html). The name of each file is a combination of the station number (e.g., Stod_105), station name (e.g., Hvanneyri), and type of table (ManMedal for monthly values, ArsMedal for annual values). The monthly mean wind speed, temperature, dewpoint, sea level pressure, and precipitation from 1991 to 2000 are used for comparison with the simulation results. The distribution of observation stations and a location map of Iceland are shown in Fig. 2. The mountainous areas in central and southern Iceland are not monitored by the observations.

\section{Evaluation of Polar MM5 simulations over Iceland}

The monthly mean climate data from 70 surface observation stations for 1991-2000 are used to evaluate the simulation results. Standard near-surface model outputs are used here. The simulated 2-m temperature is corrected from model terrain height to station elevation by using a lapse rate of $0.009^{\circ} \mathrm{C} \mathrm{m}^{-1}$; tests showed that this value gave the best results. The modeled surface pressure is corrected from model height to sea level using the hypsometric equation and the simulated 2-m temperature.

From Fig. 3a, it can be seen that the monthly mean near-surface temperature biases between simulated and

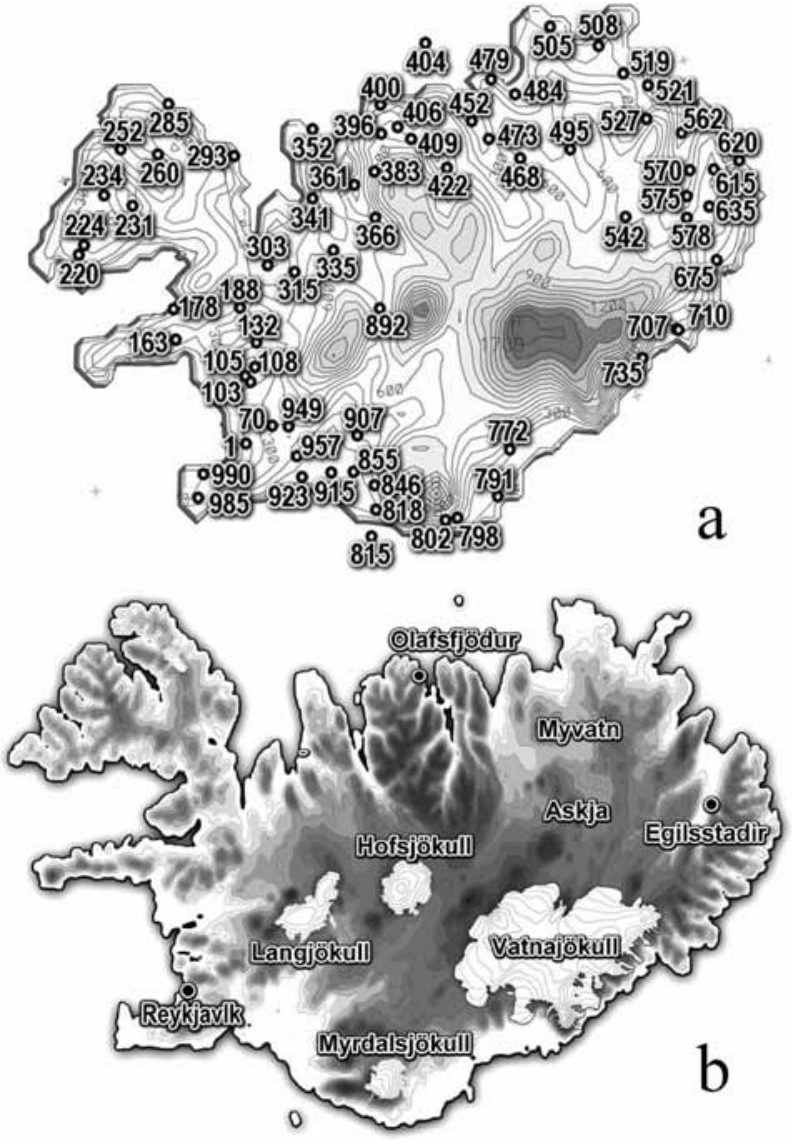

FIG. 2. (a) Meteorological stations with monthly mean climate data for Iceland. Station numbers are given. (b) Location map of Iceland.

observed values are $-2.6^{\circ}$ to $0.9^{\circ} \mathrm{C}$, root-mean-square errors (rmses) are $0.6^{\circ} \sim 2.8^{\circ} \mathrm{C}$, and the correlation coefficients are $0.98-0.99$ except for five stations at which the correlation coefficient is 0.97 . The mean bias, rmse, and correlation coefficient are $-0.9^{\circ} \mathrm{C}, 1.4^{\circ} \mathrm{C}$, and 0.99 for the 70 stations, respectively (Table 1). A cool temperature bias is found over all of Iceland except for a slight warm bias on the southwest and east coasts. Large cool temperature biases occur in northern Iceland where the terrain is very complicated. The northern observing stations tend to be located in valleys and the model resolution is too coarse to resolve such low elevations. The cool model biases may arise because, in the real world, winter valley winds mix the lower atmosphere more effectively than in the model.

The monthly mean 2-m dewpoint biases between simulated and observed are $-1.9^{\circ}$ to $0.9^{\circ} \mathrm{C}$, rmses are $0.4^{\circ} \sim 1.9^{\circ} \mathrm{C}$, and the correlation coefficients are $0.99 \mathrm{ex}-$ cept for six stations at which it is 0.98 (Fig. 3b). The mean bias, rmse, and correlation coefficient are $-0.3^{\circ} \mathrm{C}, 1.0^{\circ} \mathrm{C}$, and 0.99 , respectively (Table 1 ). Nega- 

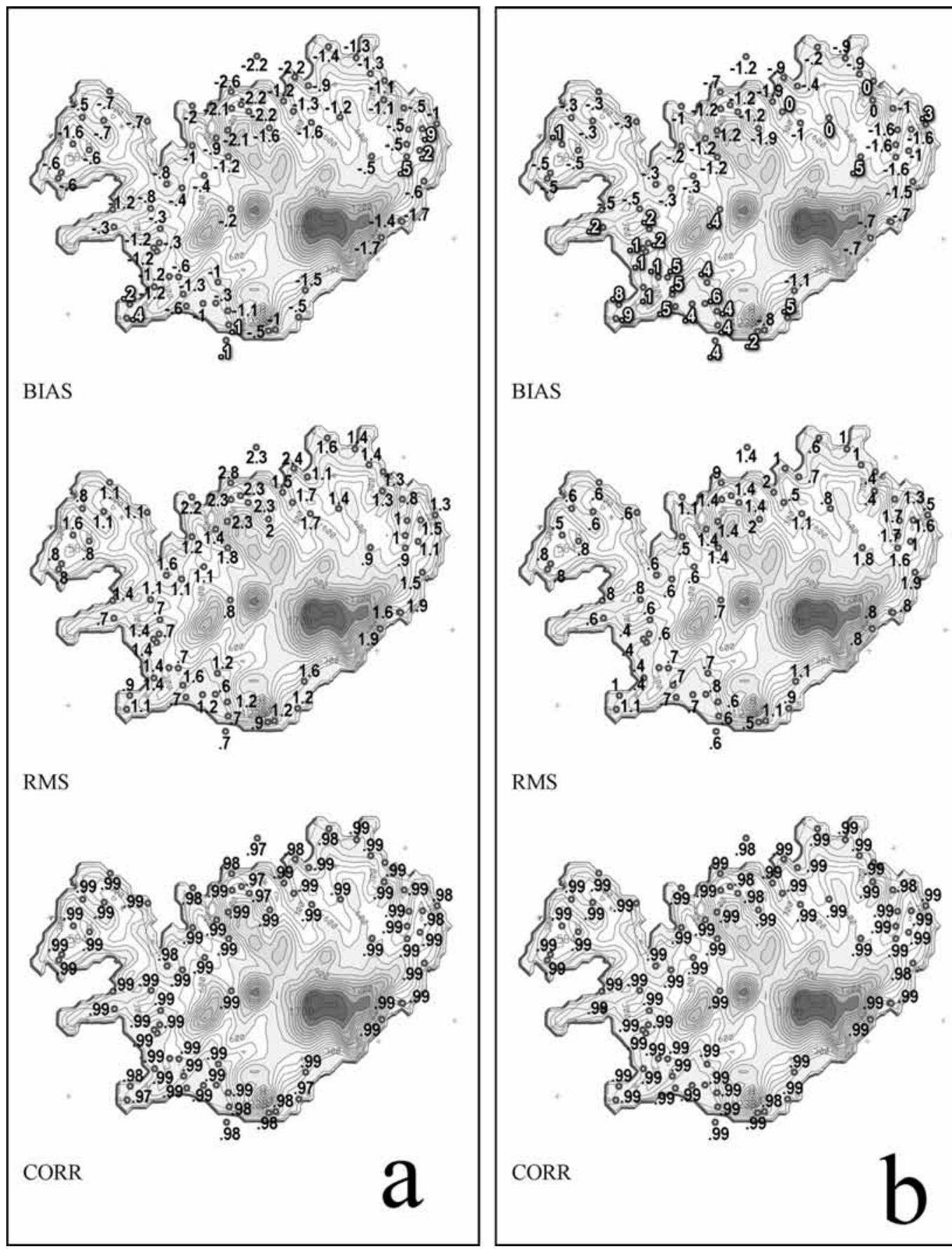

BIAS

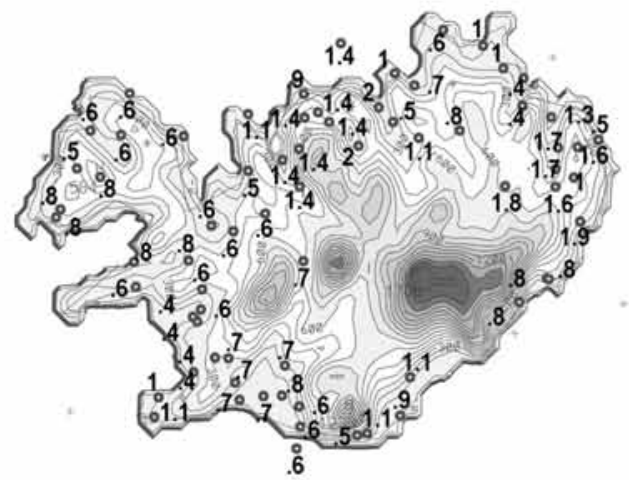

RMS

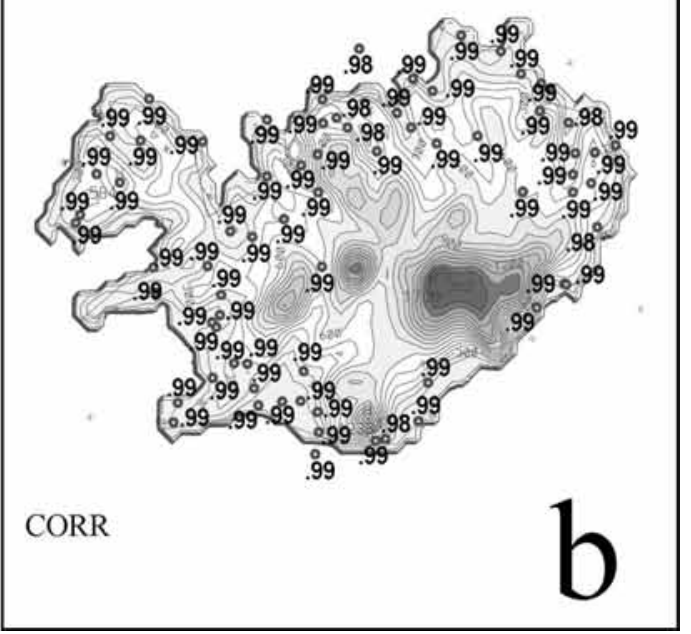

FIG. 3. The monthly mean bias, rmse, and correlation between observed and simulated by Polar MM5 from 1991 to 2000 , for (a) 2-m temperature $\left({ }^{\circ} \mathrm{C}\right)$ and (b) 2-m dewpoint $\left({ }^{\circ} \mathrm{C}\right)$. Terrain is shaded for reference. Contour interval is $100 \mathrm{~m}$. Positive bias values are highlighted.

tive dewpoint biases are found in the northern and eastern parts of Iceland, and positive biases occur in the southwest. The regions where the biases and rmses are largest are northern and eastern Iceland.

The monthly mean sea level pressure biases are -0.47 to $0.83 \mathrm{hPa}$, rmses are $0.54 \sim 0.96 \mathrm{hPa}$, and the correlation coefficients are 0.99 (Fig. 4a). The mean bias, rmse, and correlation coefficient are $0.1 \mathrm{hPa}, 0.7$ $\mathrm{hPa}$, and 0.99 , respectively (Table 1 ). Positive sea level pressure biases are found over most of Iceland.

The monthly mean near-surface wind speed biases between simulated and observed are -2.5 to $2.9 \mathrm{~m} \mathrm{~s}^{-1}$, 
TABLE 1. Average statistics of the simulated and observed monthly mean temperature, dewpoint, sea level pressure, wind speed, and precipitation from 1991 to 2000 for 70 observation stations.

\begin{tabular}{ccccc}
\hline \hline $\begin{array}{c}\text { Temperature }\left({ }^{\circ} \mathrm{C}\right) \\
\text { bias/rmse/correlation }\end{array}$ & $\begin{array}{c}\text { Dewpoint }\left({ }^{\circ} \mathrm{C}\right) \\
\text { bias/rmse/correlation }\end{array}$ & $\begin{array}{c}\text { Sea level pressure }(\mathrm{hPa}) \\
\text { bias/rmse/correlation }\end{array}$ & $\begin{array}{c}\text { Wind speed }\left(\mathrm{m} \mathrm{s}^{-1}\right) \\
\text { bias/rmse/correlation }\end{array}$ & $\begin{array}{r}\text { Precipitation }(\mathrm{mm}) \\
\text { bias/rmse/correlation }\end{array}$ \\
\hline$-0.9 / 1.4 / 0.99$ & $-0.3 / 1.0 / 0.99$ & $0.1 / 0.7 / 0.99$ & $0.4 / 1.6 / 0.76$ & $-0.5 / 43.8 / 0.72$ \\
\hline
\end{tabular}

rmses are $0.7 \sim 3.2 \mathrm{~m} \mathrm{~s}^{-1}$, and the correlation coefficients are 0.48 to 0.94 (Fig. $4 b$ ). The correlation coefficients at most stations are larger than 0.70 , and only at eight stations are the correlation coefficients smaller than 0.60 . The mean bias, rmse, and correlation coefficient are $0.4 \mathrm{~m} \mathrm{~s}^{-1}, 1.6 \mathrm{~m} \mathrm{~s}^{-1}$, and 0.76 , respectively (Table 1). Slightly larger biases are found along the coast where the terrain is complicated and the model resolution is not high enough to accurately resolve it. Monthly wind direction observations were not available, but forecast directions were tested against $6 \mathrm{~h}$ data for January and July 1998 and found to be very accurate on average (not shown). In general, Polar MM5 has reasonable forecast skill for monthly mean near-surface wind speed and can simulate the near-surface mesoscale wind climate over Iceland.

The monthly mean precipitation biases between simulated and observed are -69 to $51 \mathrm{~mm}$, rmses are 22 $\sim 87 \mathrm{~mm}$, and the correlation coefficients are 0.33 to 0.89 , with the values larger than 0.60 for all except for eight stations (Fig. 5). The mean bias, rmse, and correlation coefficient are $-0.5 \mathrm{~mm}$ (average percentage departure, $0.6 \%), 44 \mathrm{~mm}$, and 0.72 for the 70 stations, respectively (Table 1 ). The simulated precipitation is larger than observed in northern Iceland and smaller in the southern part. The comparatively high correlation coefficient indicates that the Polar MM5 simulations can reasonably reproduce the monthly precipitation variability over Iceland.

The annual mean simulated and observed spatial distributions for 1991-2000 were evaluated using pattern correlation coefficients. A pattern correlation coefficient of 1.0 indicates a perfect match between observed and simulated magnitudes. The pattern correlation coefficients for 2-m temperature, 2-m dewpoint, precipitation, sea level pressure, and $10-\mathrm{m}$ wind speed are 0.83 , $0.82,0.87,0.85$, and 0.66 , respectively. The model results capture the spatial variance of regional climate over Iceland.

To illustrate the seasonal cycle of model performance, Fig. 6 shows the monthly mean surface temperature, dewpoint, sea level pressure, wind speed, and precipitation time series of surface observation data and simulated by Polar MM5 from 1991 to 2000 for the average of all stations over Iceland. Simulated 2-m temperatures are accurate in summer but $1^{\circ} \sim 2^{\circ} \mathrm{C}$ too cold in winter. The simulated $10-\mathrm{m}$ wind speed is larger than observed in autumn by $1 \sim 2 \mathrm{~m} \mathrm{~s}^{-1}$. The simulated precipitation tends to be larger than observed in winter, and smaller than observed in summer. The simulated dewpoint and sea level pressure are well matched with the observations and no systematic biases are found. Overall, it can be seen that Polar MM5 well reproduces the observed monthly time series of sea level pressure, temperature, wind speed, and dewpoint, but with slightly reduced skill for precipitation.

The evaluation results show that Polar MM5 can reasonably simulate the spatial patterns and temporal variations of observed monthly and annual mean nearsurface temperature, dewpoint, wind speed, sea level pressure, and precipitation over Iceland. Hence, the Polar MM5 is a useful tool to investigate the Icelandic mesoscale climate, not completely resolved by the observations.

\section{Simulation results}

\section{a. Near-surface wind climate over Iceland}

The horizontal pressure gradient is the primary driving force for the wind, but over land it is well known that topography, roughness, and variations in thermal stratification also affect it. In coastal areas those factors related to the land-sea transition contribute to a complex wind field and affect the wind even at large distances from the coast. Spatial variations of the wind field over Iceland are difficult to measure directly. The numerical mesoscale model can be used to rebuild them.

Figures 7a,b show the streamlines of mean nearsurface winds in winter (December-February, 19922000, with the winter year corresponding to January and February) simulated by Polar MM5. The temperature difference between land and sea is large and negative during night and day in winter (not shown). The near-surface wind directions are from land to sea. Downslope winds can be seen clearly at Hofsjökull, Langjökull, Myrdalsjökull, and Vatnajökull, Iceland. Strong downslope winds are found over Vatnajökull ice cap. The downslope winds over Iceland generally merge into the synoptic-scale circulation along the coast, and form a convergent wind shear zone to the south of Iceland with southwest winds farther offshore. 

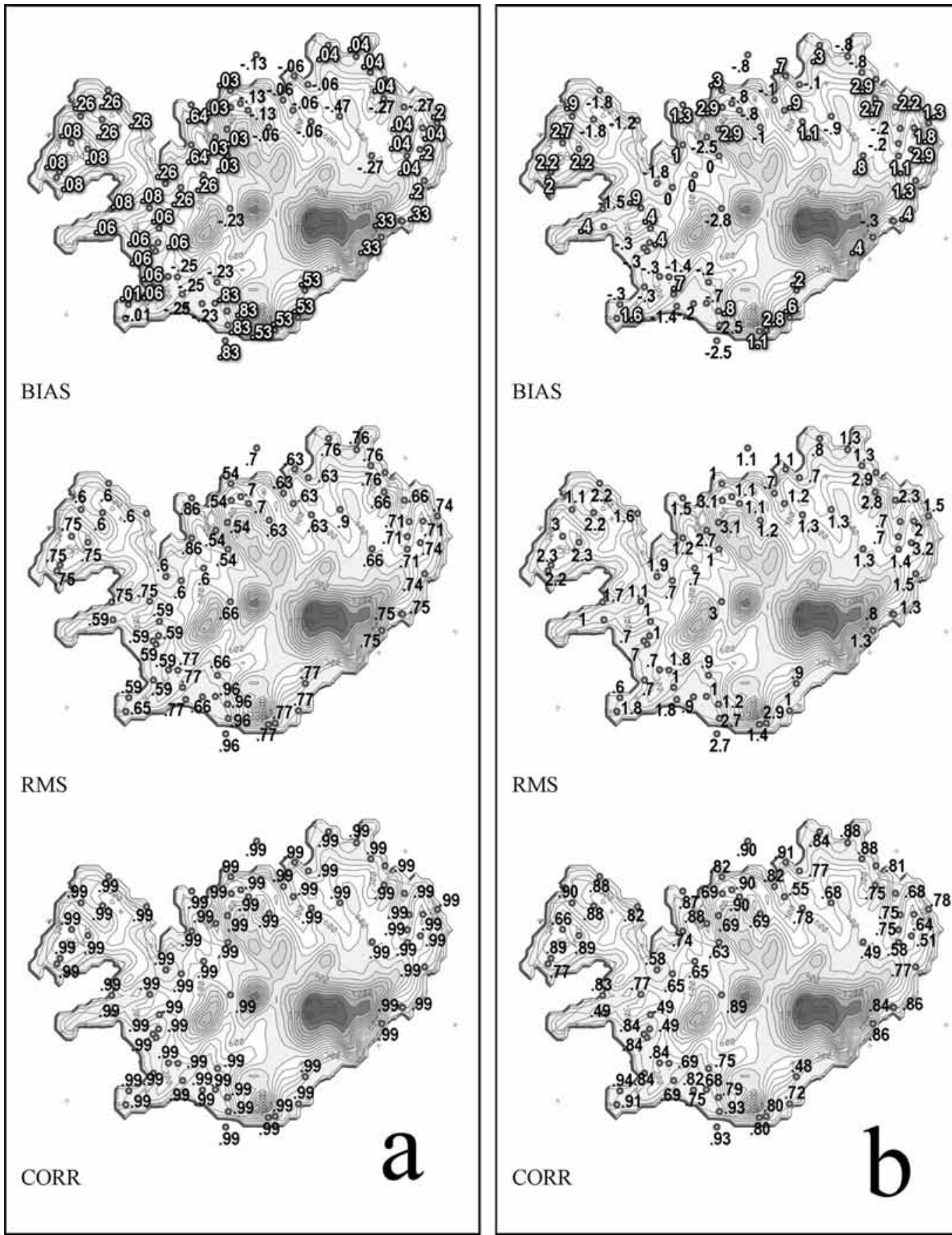

BIAS

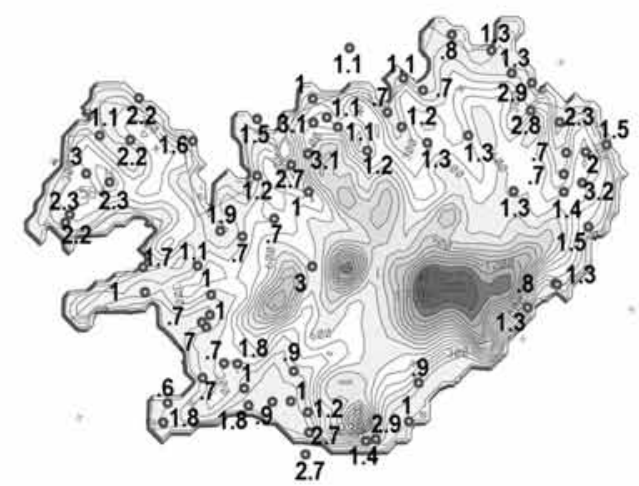

RMS

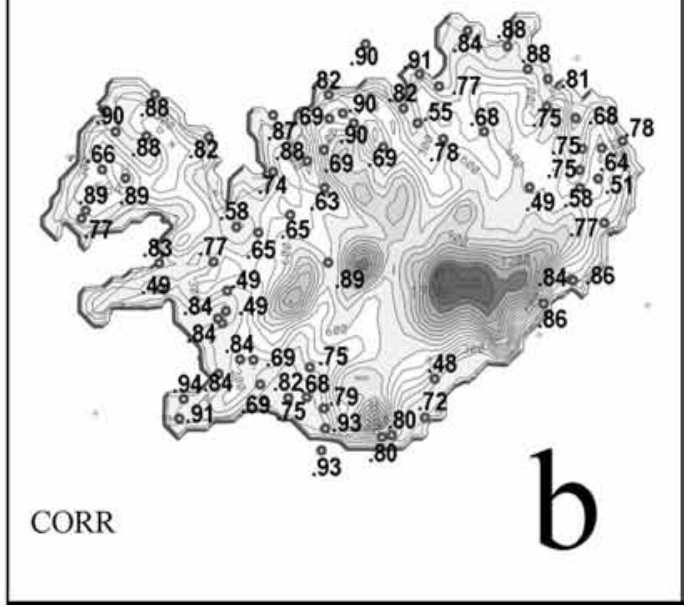

FIG. 4. Same as in Fig. 3, but for (a) sea level pressure (hPa) and (b) 10-m wind speed ( $\mathrm{m} \mathrm{s}^{-1}$ ).

The near-surface winds in winter are katabatic and they constitute one of the important winter climatic features over Iceland. The surface winds over Iceland display a high degree of persistence with mean directions related to the local topography. Orography constrains the atmospheric boundary layer motions via channeling into valleys, flow around isolated obstacles, and cold air damming along mountainous terrain. The difference of temperature between land and sea determines the air motions near the coast, and the scale of Iceland is small so that the above factors dominate the overall nearsurface wind pattern during winter.

The simulated streamlines of mean near-surface winds in summer (June-August, 1991-2000) are shown in Figs. 7c,d. The main difference between winter and summer is the marked summer diurnal variation of 


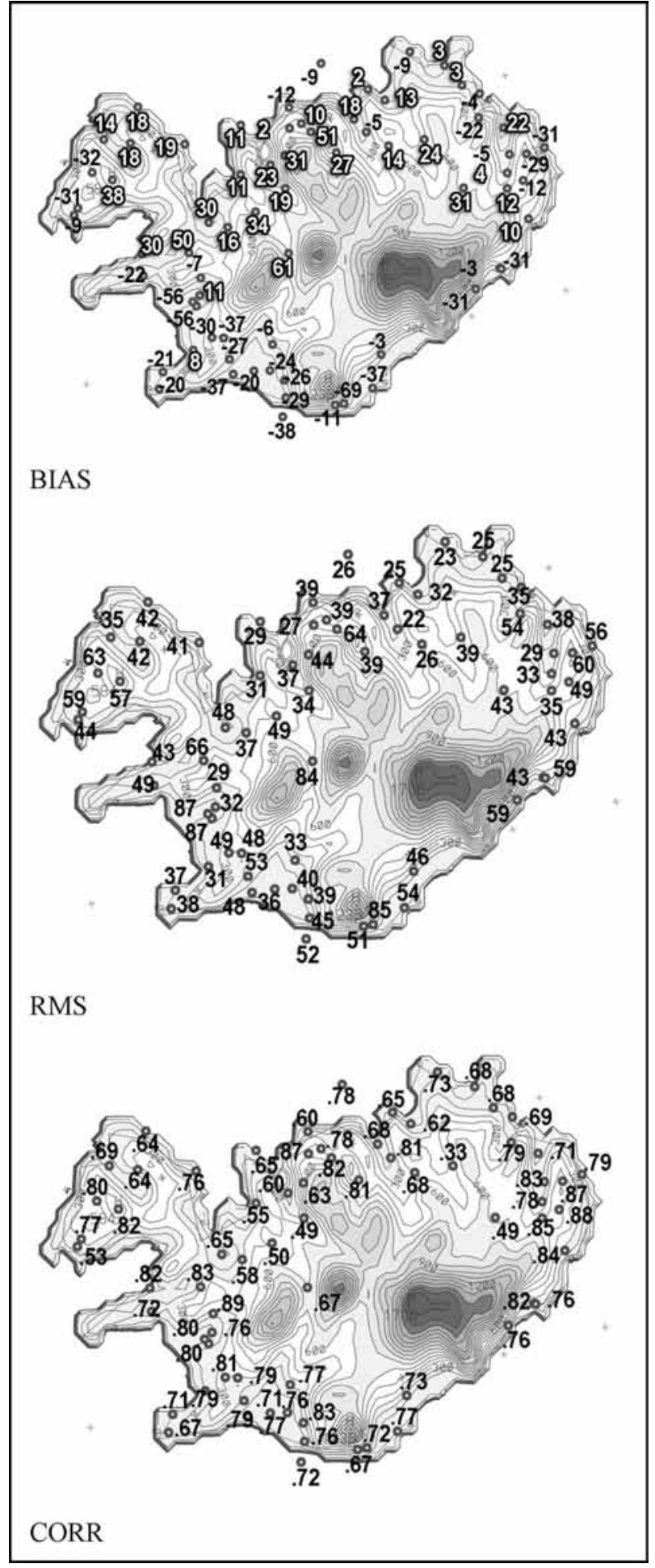

FIG. 5. Same as in Fig. 3, but for precipitation (mm). temperature (see section $4 \mathrm{~b}$ ). The temperature over land is higher than that over the sea in the afternoon and lower during the morning. The corresponding nearsurface wind pattern differs as well. Late at night and in the morning, the near-surface winds feature a katabatic pattern similar to that in winter but not as strong because of the smaller temperature difference between land and sea; the convergent wind shear zone is over the sea close to the south coast. Two mesoscale cyclonic vortices can be seen at the northeast and southwest corners of Iceland, resulting from the convergence between the environmental circulation and the local katabatic wind. In the afternoon, the near-surface winds feature an upslope pattern because of the higher temperature over land; the observational study by Kaltenböck and Obleitner (1999) suggests that coastal sea breezes are a frequent occurrence in summer. The exception is over the Vatnajökull ice cap where downslope winds persist (cf. Oerlemans et al. 1999). The mesoscale vortex, which is located to the southwest in the morning, becomes a convergence line in the afternoon, and the other mesoscale vortex moves close to Egilsstadir, Iceland, and becomes a convergence region.

\section{b. Surface temperature and moisture variations}

Figure 8 shows the average monthly 2-m air temperature and 2-m mixing ratio in January and July. The distribution patterns mirror the terrain for both months, with temperature and mixing ratio minima located at the summit of mountains. The January temperature over the ocean is mostly higher than $0^{\circ} \mathrm{C}$, and the temperature inland is below $0^{\circ} \mathrm{C}$; it is $0^{\circ} \sim 1^{\circ} \mathrm{C}$ along the coast, and $-12^{\circ} \mathrm{C}$ over the Vatnajökull ice cap. This result is close to the January observational analysis of Einarsson (1984) for 1931-60. A strong horizontal temperature gradient is found along the southern coast in January but is much weaker along the northern coast. The daily range of near-surface air temperature is very small in January (not shown), which means that the land remains colder than the sea throughout the winter. It is this temperature structure that produces the katabatic winds discussed in section $4 \mathrm{a}$. The steady katabatic winds continuously advect cold air from the land to the sea. This advection process decreases the horizontal temperature gradient along the north coast but forms a strong horizontal temperature gradient region south of Iceland as a result of the northerly katabatic winds, the southwest flow from the large-scale circulation (Figs. 8a1 and 7), and the local SSTs.

The summer distribution pattern of 2-m surface air temperature (Fig. 8a2) is different from that of winter; there is no persistent strong horizontal temperature 


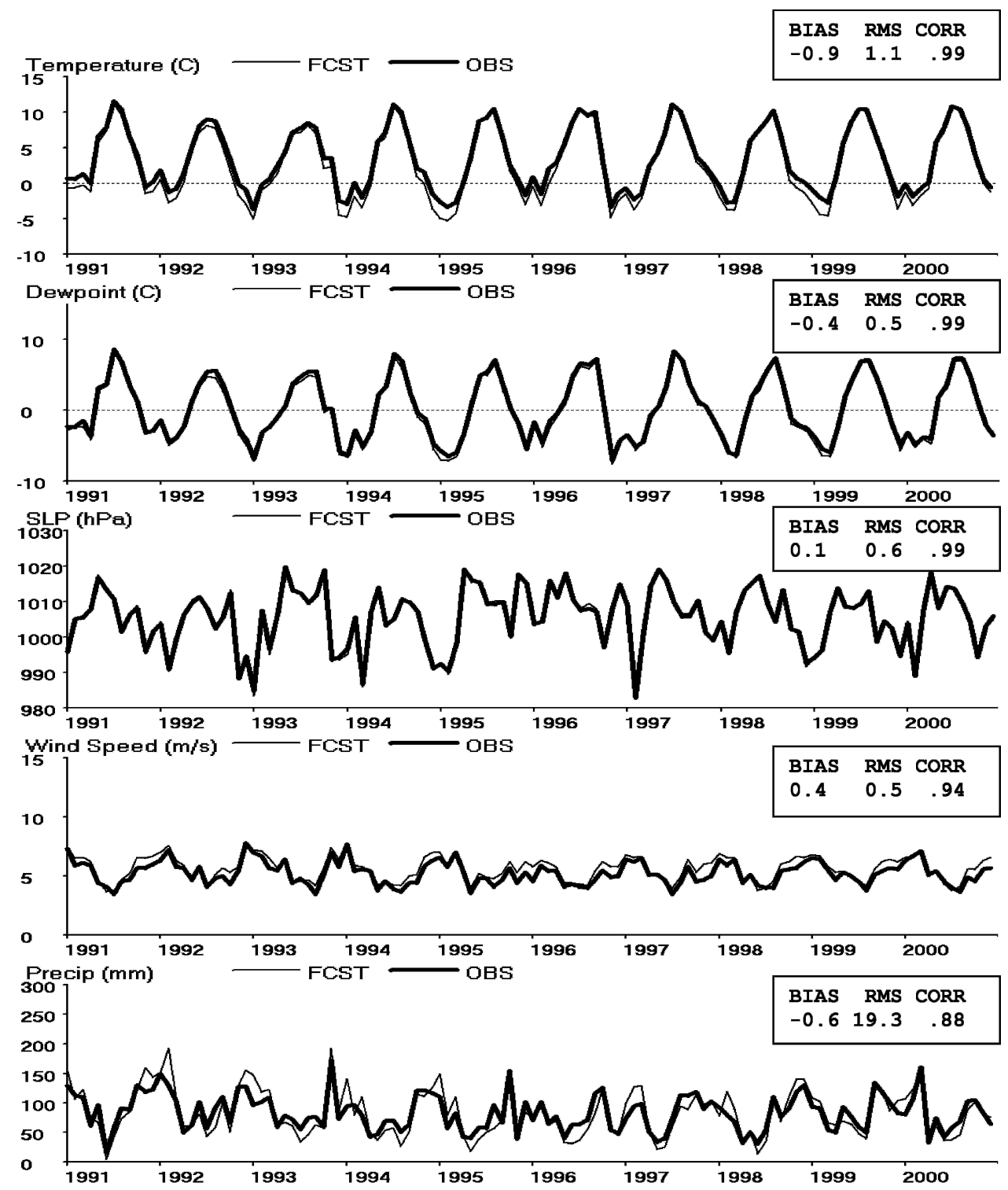

FIG. 6. The average for all stations of monthly mean surface temperature $\left({ }^{\circ} \mathrm{C}\right)$, dewpoint $\left({ }^{\circ} \mathrm{C}\right)$, sea level pressure $(\mathrm{hPa})$, wind speed $\left(\mathrm{m} \mathrm{s}^{-1}\right)$, and precipitation $(\mathrm{mm})$ time series from observations and simulated by Polar MM5 from 1991 to 2000. The wind speed is at $10 \mathrm{~m}$ above ground. The temperature and dewpoint are at $2 \mathrm{~m}$ above ground. Bias, rmse, and correlation are calculated for average observed and modeled time series, i.e., using a different approach to Table 1.

gradient along the coast. It only occurs during summer in the early morning, and it weakens and disappears after sunrise. The land-sea front and land breeze are limited to the coastal region in the early morning and the temperature minima are at the summit of mountains: $5^{\circ} \mathrm{C}$ at Langjökull, Hofsjökull, and Myrdalsjökull and $0^{\circ} \sim 1^{\circ} \mathrm{C}$ over the Vatnajökull ice cap. The daily range of near-surface air temperature over land is prominent in July, about $2^{\circ} \sim 4^{\circ} \mathrm{C}$ (Fig. 8a3). These results are close to Einarsson's (1984) observational analysis for July.
The average monthly $2-\mathrm{m}$ mixing ratio is low over Iceland, and there is no obvious minimum in January (Fig. 8b1). The prominent dry region is over the Vatnajökull ice cap in July (Fig. 8b2). A distinct daily range of near-surface mixing ratio is found in July over land (Fig. 8b3). As expected, the 2-m mixing ratio behavior generally parallels that of 2-m air temperature.

The average 2-m surface temperature has a signature of the North Atlantic Oscillation (NAO), which is the dominant mode of interannual climate variability over and around the North Atlantic Ocean. Rogers's (1984) 

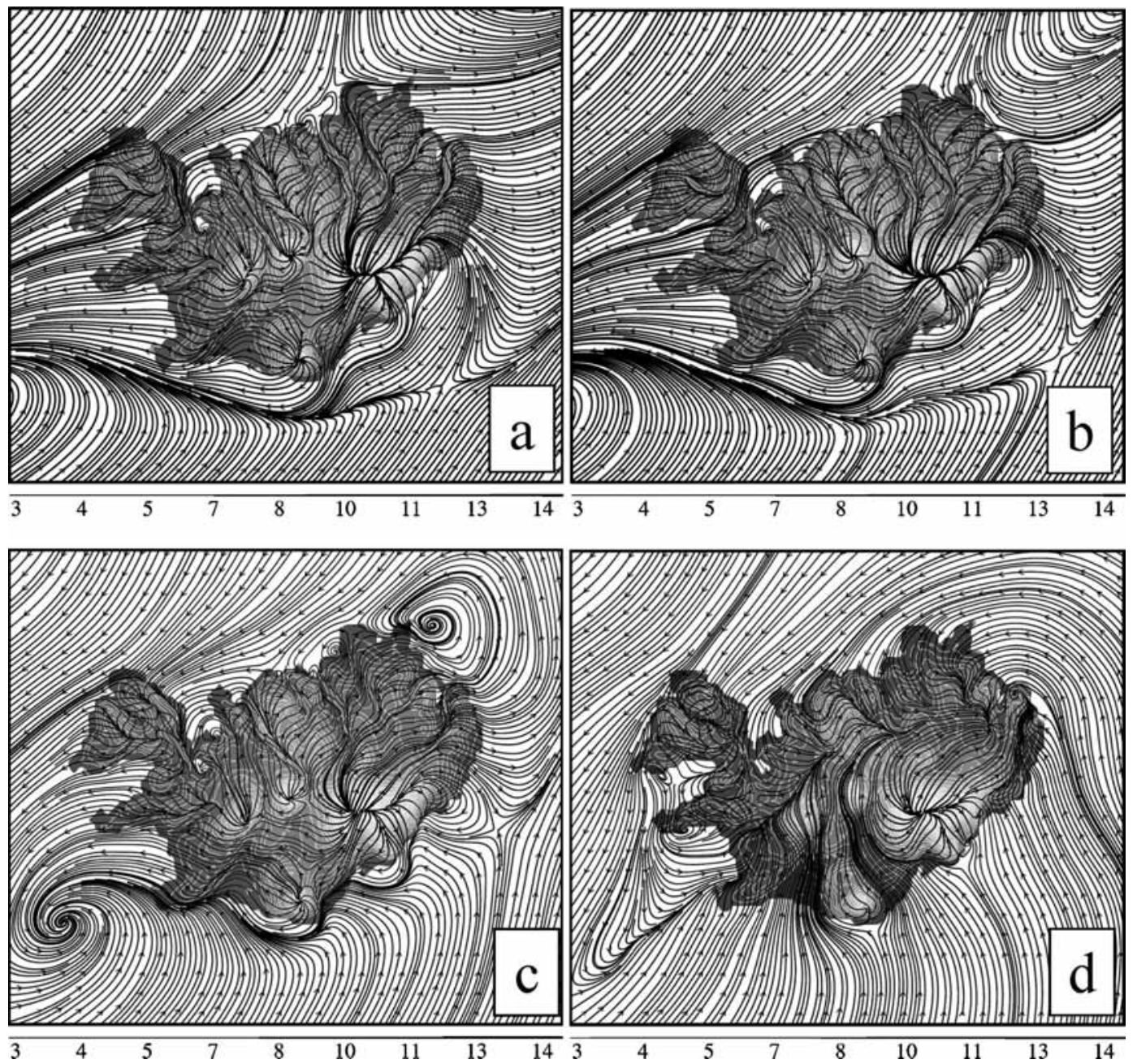

FIG. 7. Streamlines of mean near-surface winds (1991-2000) over Iceland simulated by Polar MM5 at (a) 0600 $(0500$, LT) and (b) 1800 UTC (1700, LT) in winter; (c) 0600 and (d) 1800 UTC in summer. Terrain is shaded for reference; contour interval is $100 \mathrm{~m}$. Streamline width is proportional to wind speed with the scale at the bottom of each plot.

normalized seasonal NAO index (available online at $\mathrm{http} / / /$ polarmet.mps.ohio-state.edu/) is used to characterize this variability. The model simulated pressure for Iceland closely matches the observations (section 3) while the Azores lies outside the model domain, thus guaranteeing that the Rogers-observed NAO index monitors the NAO variability simulated by the model. Rogers's NAO index is taken to be larger than 1 for the "NAO positive phase" and less than -1 for the "NAO negative phase." Figures 9a,b show the surface temperature difference between positive and negative NAO phases simulated by Polar MM5 during the winter half year [October-March (ONDJFM)] and the summer half year [April-September (AMJJAS)]. The 2-m surface temperature is $3^{\circ} \mathrm{C}$ colder in the positive NAO phase than during the negative NAO phase in winter over most of Iceland. For summer time, the NAO signature is not nearly as marked, with a small negative region in the southwest and a $1{ }^{\circ} \mathrm{C}$ positive region along the northeastern coast. The 2-m surface temperature for the NAO positive phase is colder than that for the NAO negative phase in winter and warmer in summer.

Figures $9 \mathrm{c}, \mathrm{d}$ show the simulated $2-\mathrm{m}$ mixing ratio difference between positive NAO and negative NAO phases for the winter half year and the summer half year. The 2-m mixing ratio is $0.5 \sim 0.7 \mathrm{~g} \mathrm{~kg}^{-1}$ less in the positive NAO phase than that in the negative NAO phase in winter. During summer, the 2-m mixing ratio is on average $0.2 \sim 0.3 \mathrm{~g} \mathrm{~kg}^{-1}$ larger in the positive NAO phase than that in the negative NAO phase. A clear local pattern occurs over Iceland during summer, which 

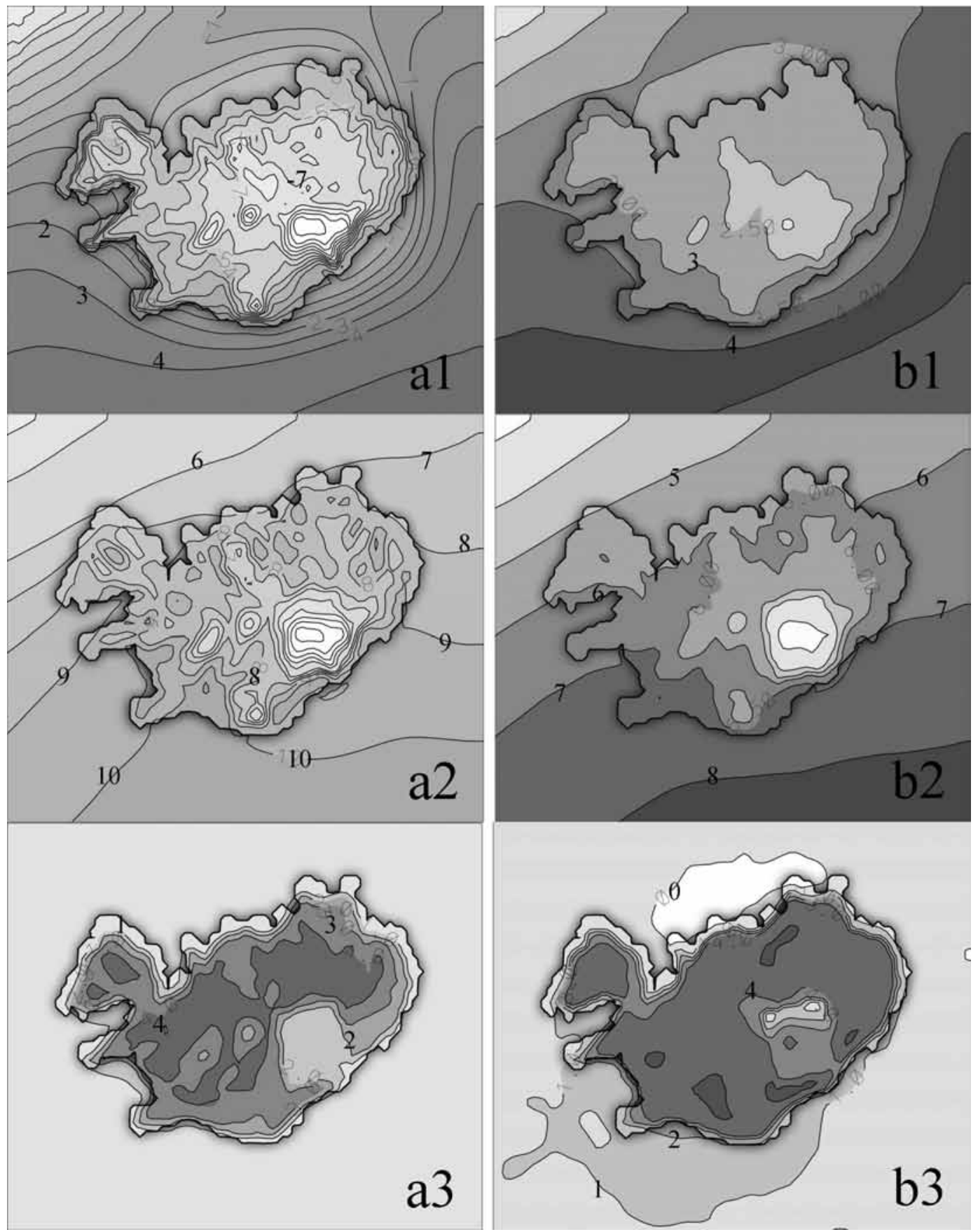

FIG. 8. The monthly mean 2-m surface temperature: (a1) in Jan, (a2) in Jul, (a3) the difference between 1800 and 0600 UTC in Jul, the contour interval is $1^{\circ} \mathrm{C}$. (b1)-(b3) Same as (a1)-(a3) but for the monthly mean 2-m mixing ratio; the contour interval is $0.5 \mathrm{~g} \mathrm{~kg}^{-1}$ for (b1) and $1 \mathrm{~g} \mathrm{~kg}^{-1}$ for (b2) and (b3).

has a minimum in the southwestern part and a $0.4 \mathrm{~g}$ $\mathrm{kg}^{-1}$ maximum along the northeastern coast. The seasonal NAO signature varies for 2-m mixing ratio over Iceland, the same as for 2-m air temperature.

During the NAO positive phase in the winter half year, a deeper-than-normal Icelandic low results in more and stronger winter storms crossing Iceland. The Greenland high and associated northerly winds are weaker than during the NAO negative phase (cf. Figs. $12 \mathrm{c}, \mathrm{d}$, presented later). Iceland is primarily controlled by strong southwest winds that advect cold air from Greenland and Labrador (not shown). Thus, 2-m tem- 

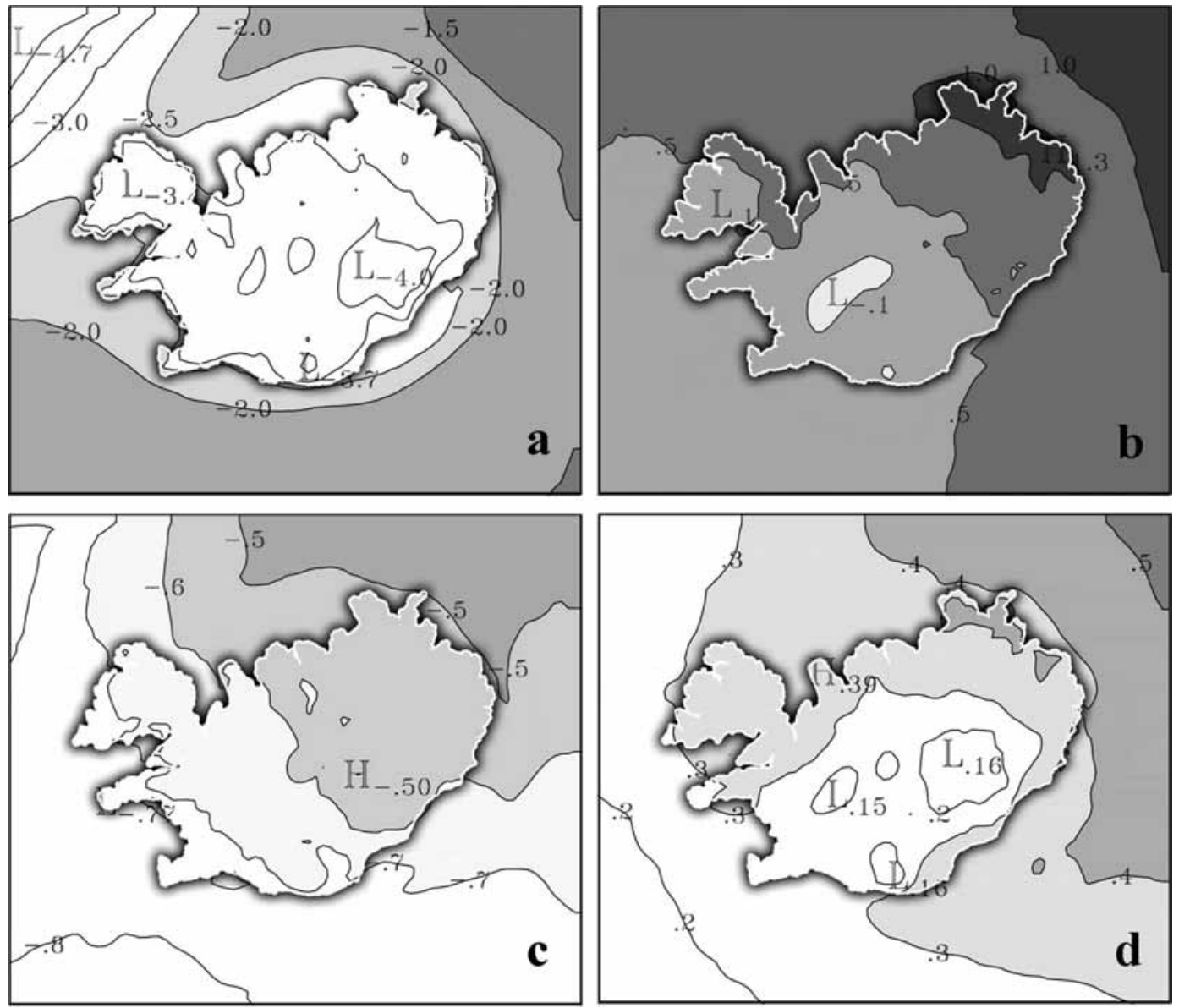

FIG. 9. The mean surface temperature difference between positive and negative NAO phase months from 1991 to 2000: (a) winter half year (ONDJFM), (b) summer half year (AMJJAS); the contour interval is $0.5^{\circ} \mathrm{C}$. The mean surface mixing ratio difference between positive and negative NAO phase months from 1991 to 2000 in the (c) winter half year and the (d) summer half year. The contour interval is $0.1 \mathrm{~g} \mathrm{~kg}^{-1}$.

perature and 2-m mixing ratio are lower during the NAO positive phase. During the summer half year, the large-scale wind direction is again from the southwest for the NAO positive phase (Fig. 12e) and northeast for the NAO negative phase (Fig. 12f). The large-scale maritime flow at this time of year has a more southerly component and is warmer and moister than normal; as a result surface temperature and humidity increases over Iceland.

\section{c. Precipitation variations}

Modeling the spatial and temporal distribution of precipitation is one of the most challenging problems for mesoscale regional climate simulations. The seasonal changes in the cyclonic circulation lead to the annual cycle of precipitation and the spatial distribution of precipitation follows the terrain. Furthermore, climate variability in Iceland is enhanced by the NAO phenomenon, primarily during the colder months. As a result of these factors, precipitation is extremely variable in space and time. In a general sense, there are two precipitation seasons, one wet that occurs from October to April, and the other dry from May to September. The annual distribution of precipitation over Iceland is directly dependent on the position of the Icelandic low.

The observed mean annual precipitation distribution for 1931-60 is shown in Fig. 10a. This analysis is derived from mostly low elevation station precipitation observations (not corrected for systematic errors, like wind effects) and supplemented by hydrologic observations and snow accumulation measurements for subjective evaluation in areas with no direct precipitation data (Einarsson 1984; T. Jonsson 2004, personal communication). The minimum annual precipitation is about 400 $\mathrm{mm} \mathrm{yr}^{-1}$ and occurs on the northeastern basin regions of Myvatn and Askja, Iceland. The mountain zones have an average annual precipitation of $2800 \mathrm{~mm} \mathrm{yr}^{-1}$. 

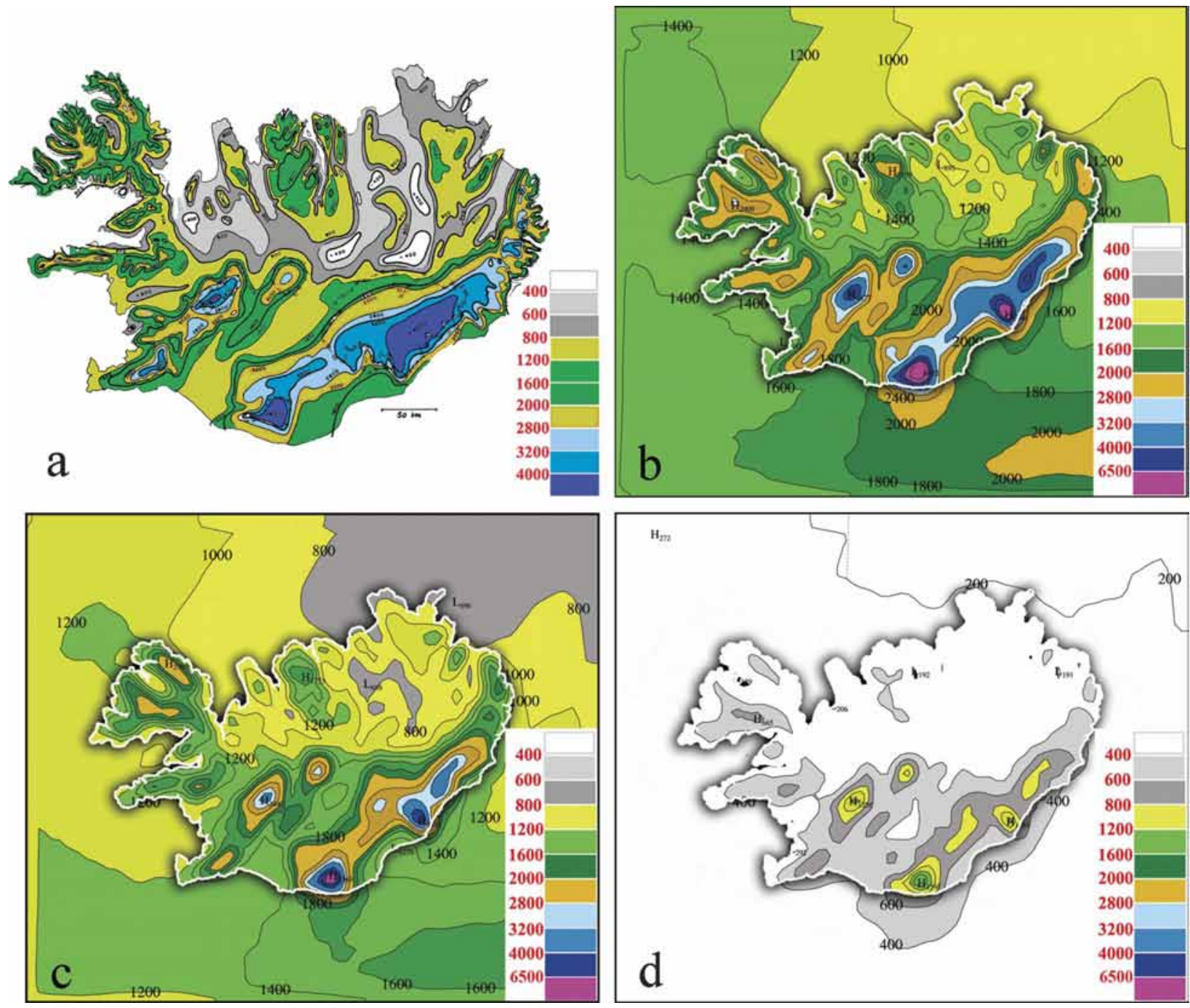

FIG. 10. (a) The observed mean annual precipitation distribution for 1931-60, which is derived from station precipitation observations and supplemental data (unit: mm). (b) The annual mean precipitation in (1991-2000) simulated by Polar MM5 V3.5 (unit: mm). (c) The mean winter precipitation for 1991-99 (15 Sep-30 Apr) simulated by Polar MM5 (mm). (d) Same as (c) but for summer (1 May-14 Sep).

The heaviest precipitation is located near the southeast coast of Iceland, with average values of about $3000 \mathrm{~mm}$

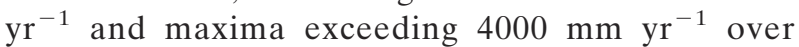
Myrdalsjökull and south of Vatnajökull. Given that the relationship between large- and regional/local-scale atmospheric behavior is highly nonlinear (Moss et al. 1994), atmospheric physically based models need to be extended to these regions and scales to complement approximate observational syntheses.

The long-term mean annual precipitation simulated by Polar MM5 for 1991-2000 is shown in Fig. 10b. The overall precipitation distribution over Iceland is reasonably well simulated by Polar MM5, especially in the southwest, south, and southeast regions. There are shortcomings to many of the smaller-scale precipitation features simulated by Polar MM5. The model cannot capture the detailed structure and magnitude of the "observed" precipitation in northwestern and northern Iceland. Rögnvaldsson et al. (2004) applied a statistical model and MM5 to estimate the precipitation in the complex terrain over Iceland. The results suggest that, on average, MM5 simulates more precipitation than observed with the contrast being greater in the northern part of Iceland than in the south. To some extent this difference can be explained by gauge measurements not recording all of the solid precipitation during strong wind events, that is, the observed values in north and northwestern Iceland (Fig. 10a) are probably too small. The computed annual precipitation amounts at Langjökull and Hofsjökull are larger than observed. It 
seems that the $8-\mathrm{km}$ model resolution is still too coarse to resolve all the observed small-scale variations of precipitation.

To investigate the effects of the model resolution on our simulated precipitation, two simulations were carried out with different horizontal resolutions ( 8 and 4 $\mathrm{km}$ ) but with the same 28 vertical levels for one winter month, December 2002. Figure 11 shows the two simulated precipitation patterns. It can be seen that there is a general increase in maximum values of simulated precipitation with increase in horizontal resolution. More detailed and realistic results are obtained with a resolution of $4 \mathrm{~km}$. For example, simulated precipitation amounts for the two peninsulas along the west coast are more realistic with 4-km resolution (Fig. 11b) than with 8 -km resolution (Fig. 11a) when compared to the observed distribution in Fig. 10a. The results show that the simulation results can be improved somewhat by increasing model resolution (consistent with Olafur and Olafsson 2002) but this requires an order of magnitude more calculations.

When baroclinic systems move over a mountain range in high and midlatitudes, the precipitation from the system intensifies over and sometimes upwind of the slope of the mountain barrier. The maximum precipitation occurs on the lower windward slopes in almost immediate response to the orographically induced lifting of the air such that the maximum precipitation may occur well below the summit of the range (e.g., Frei and Schaer 1998). To compare the difference between the simulated (Fig. 10b) and observed (Fig. 10a) precipitation distribution over mountainous areas, the high-resolution terrain $(4 \mathrm{~km})$ was overlain over the observed and simulated precipitation. The comparisons showed that the precipitation maxima for the 10-yr simulation are located on the slope of the mountains not at the summits; this differs from the observed precipitation (Fig. 10a) in which the maximum precipitation is located at the top of the mountains. The precipitation distribution on mountain slopes is probably sensitive to wind speed and MM5 is able to deal with this effect. Thus the simulated precipitation is likely to be more reasonable than the observed description.

Figures 10c,d show the winter (15 September-30 April) and summer (1 May-14 September) precipitation spatial distributions. Consistent with the cyclonic forcing changes, the winter amounts are much larger than those during the summer (very similar to the observational results quoted by Einarsson 1984). However, the spatial distribution is maintained in each season, reflecting the dominant control of orography, land use, model physics, and the persistent atmospheric circulation on the precipitation distribution.
Figure 12 shows simulated monthly precipitation anomaly and the streamlines of monthly mean nearsurface winds for NAO positive and NAO negative phases simulated by Polar MM5. The Icelandic low is stronger in NAO positive phase than during the negative phase and the center of Icelandic low is located just to the southwest of Iceland. The Greenland high is weaker in the NAO positive phase and the resulting northerly winds are weaker, and most of Iceland is controlled by southwest winds. The southwesterly nearsurface winds flow upslope over most of Iceland and result in precipitation increases throughout the year. For the NAO negative phase, Iceland is controlled by northeasterly winds, and precipitation decreases. For both the NAO positive and negative phases in winter, the near-surface wind pattern over Iceland is katabatic. For the three time periods, the largest changes of precipitation are in southeastern Iceland for the NAO positive phase and in southwestern Iceland during the NAO negative phase. The winter NAO index decreased during the 1990s (not shown), and the precipitation change (introduced in Fig. 15) is consistent with the NAO precipitation analysis (Fig. 12).

In general the precipitation over Iceland is positively correlated to the NAO index. In a positive NAO year, precipitation over Iceland is larger than average, whereas in negative NAO years, the precipitation is reduced.

\section{d. Trend of annual precipitation over Iceland from 1991 to 2000}

Figure 13 shows the interannual variations of precipitation simulated by Polar MM5 at the T12e and B16d sites over the Vatnajökull ice cap, for winter, summer, and annual totals along with observed winter snow accumulation from ice cores (data provided by $\mathrm{H}$. Björnsson; cf. Björnsson et al. 1998) for 1992-2000. Snow accumulation is the net result of precipitation, evaporation/sublimation, and drifting. Evaporation/sublimation is likely small in winter, and the net drifting effects are unknown but probably small, so precipitation is equated with accumulation. The precipitation amounts at the grid points retrieved from simulations are interpolated to the observation locations. It is seen that the observed linear decrease of winter accumulation is reasonably captured by the simulated winter precipitation. The precipitation simulated by Polar MM5 is slightly less than observed from 1992 to 1996 in winter at the T12e site, but larger than observed from 1997 to 1999. At the B16d site, the simulated precipitation is larger than observed after 1994. T12e is located on the western part of the Vatnajökull ice cap at the northwestern margin of a zone of a very large precipitation gradient, 

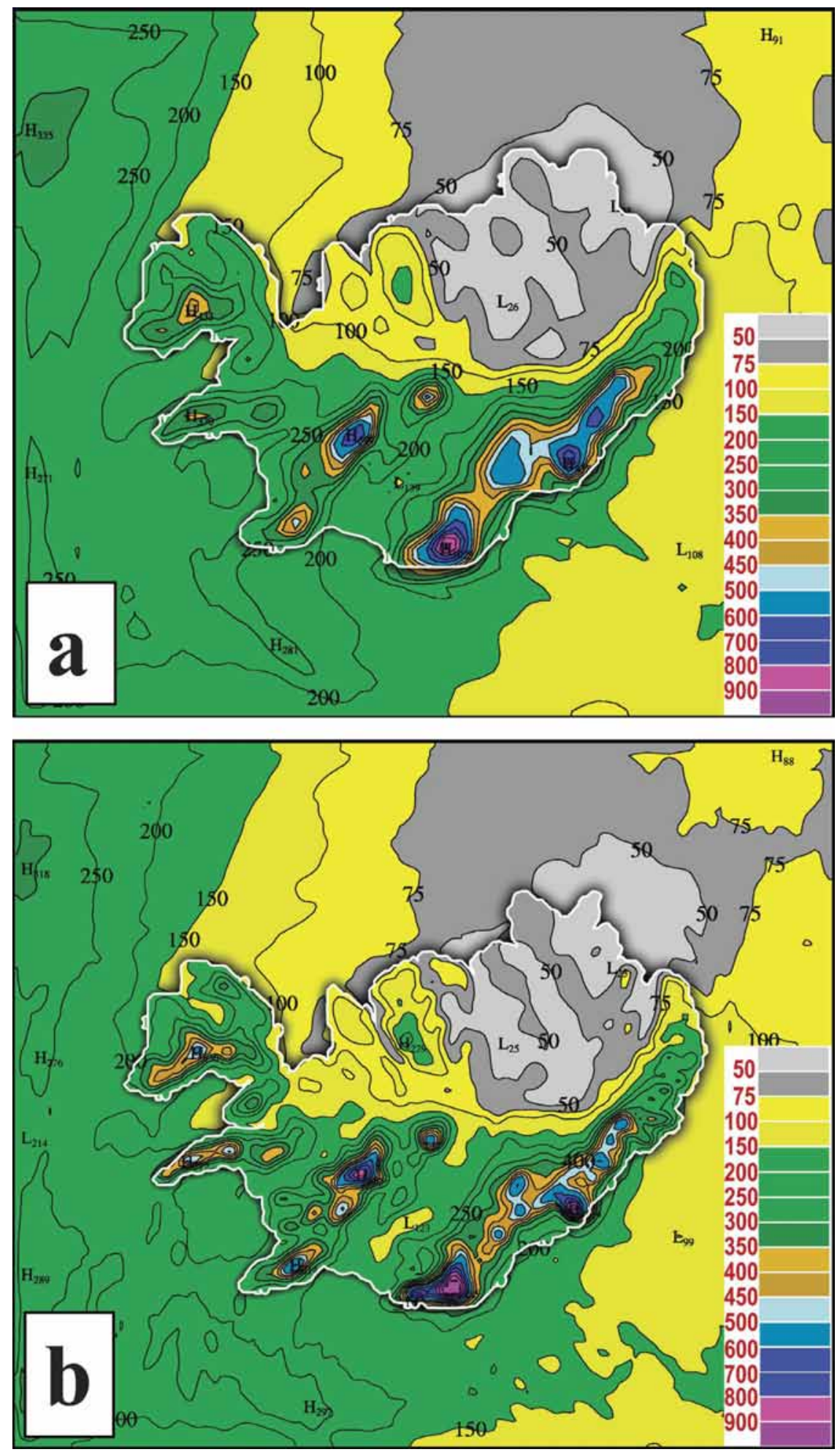

FIG. 11. Accumulated precipitation (mm) for Dec 2002 with (a) 8- and (b) 4-km horizontal resolution. 

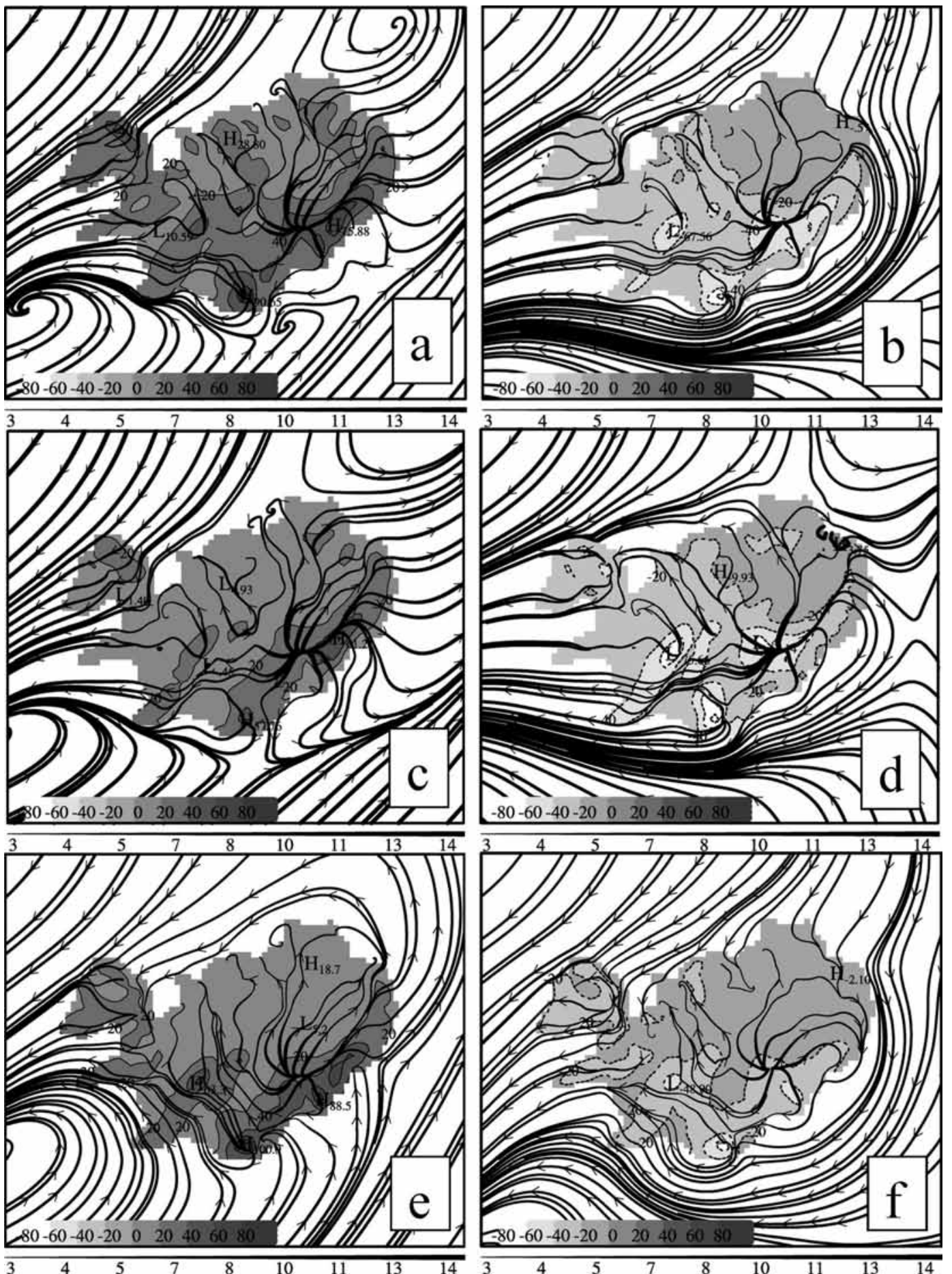

FIG. 12. The simulated monthly precipitation anomaly and 10-m wind for the 1991-2000 NAO (a) positive and (b) negative phases; NAO (c) positive and (d) negative phases for the winter half year; NAO (e) positive and (f) negative phases simulated for the summer half year. Contour interval is $20 \mathrm{~mm}$ and negative values are dashed. Width of streamlines is proportional to wind speed with the scale shown at the bottom of each figure. 


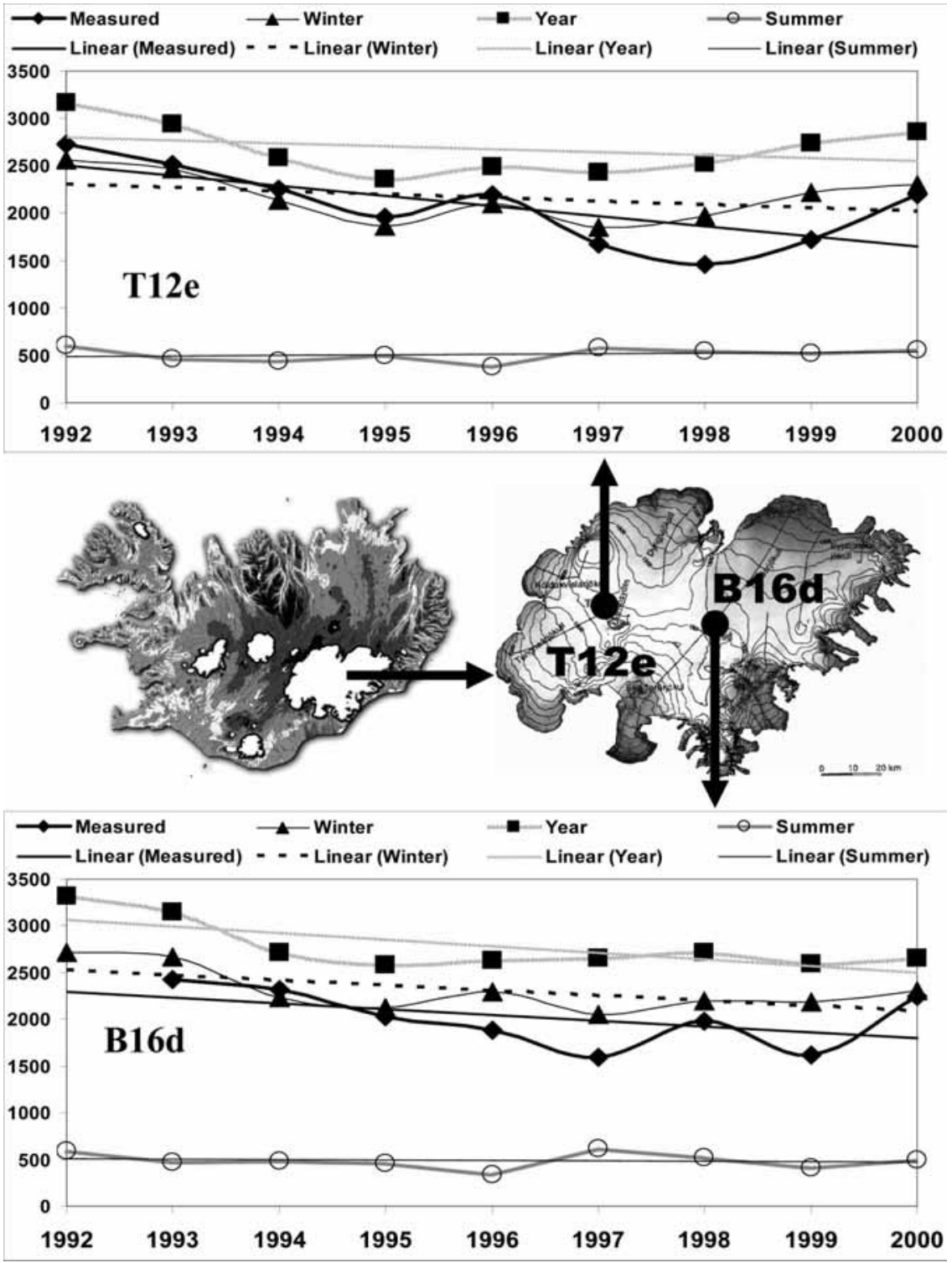

FIG. 13. The interannual variations of the observed winter (Sep-Apr) accumulation and simulated winter, annual, and summer (May-Aug) total precipitation $(\mathrm{mm})$ at the T12e and B16d sites during 1992-2000.

and B16d is at the south central part of the ice cap where there is also a large precipitation gradient. A slight shift in the model simulation will easily give a different precipitation amount. If the model cannot simulate the mesoscale features, it is difficult to get a skillful precipitation result at both sites only $40 \mathrm{~km}$ apart (or five grid lengths), so Polar MM5 has skill in capturing the terrain-forced precipitation over Iceland. The year-to-year variations in observed winter accumulation are reasonably well represented by the simulated precipitation at both $\mathrm{B} 16 \mathrm{~d}$ and $\mathrm{T} 12 \mathrm{e}$. The winter precipitation decrease determines the annual signal, and there is no significant change in summer. During summer the simulated precipitation is about $500 \mathrm{~mm}$ at both sites, and the year-to-year variations are very small.

The locations of the ice core sites and statistics of the simulated precipitation and observed accumulation from 1992 to 2000 in winter are shown in Table 2. The statistics describe the temporal and spatial relationships between the observed winter mean accumulation and modeled winter precipitation. The comparatively high coefficients show that Polar MM5 can well capture the winter-to-winter variations of precipitation over the ice 
TABLE 2. Locations of the ice core sites and statistics of the simulated precipitation and observed accumulation (mm) from 1992 to 2000 in winter.

\begin{tabular}{cccccccc}
\hline \hline Site & ${ }^{\circ} \mathrm{N}$ & ${ }^{\circ} \mathrm{W}$ & Bias & Rmse & Correlation & Avg simulated precipitation & Avg observed accumulation \\
\hline T12e & 64.44 & 17.46 & 88 & 262 & 0.80 & 2164 & 2076 \\
B16d & 64.39 & 16.70 & 196 & 320 & 0.70 & 2306 & 2010 \\
\hline
\end{tabular}

cap. The linear trends of modeled precipitation and observed accumulation at sites T12e and B16d from 1992 to 2000 in winter are given in Table 3 and reasonable agreement is found. Whereas the temporal variability of precipitation is well represented, the modeled spatial variability is less satisfactory. The simulated precipitation increases from T12e to B16d whereas observed accumulation decreases slightly. This error again shows that the model resolution is still too low to accurately capture the small-scale features of the precipitation over the ice cap.

The spatial distribution of the slope of the linear regression line of annual precipitation from Polar MM5 for 1991-2000 has been computed, and the results are shown in Fig. 14. The annual modeled precipitation decreases for all Iceland except the northeastern part, specifically the Askja basin, the northeast coast, and the coast close to Olafsfjödur, Iceland, where the precipitation increases by about $0 \sim 26 \mathrm{~mm} \mathrm{yr}^{-1}$. The maximum decreases of modeled precipitation exceed $150 \mathrm{~mm} \mathrm{yr}^{-1}$ near Hofsjökull, Langjökull, Myrdalsjökull, and the Vatnajökull ice cap, and correspond to $30 \%-50 \%$ decreases in annual precipitation between 1991 and 2000. The simulated results are in good qualitative agreement with those obtained from station precipitation records (Fig. 14b), but the large mountain-related decreases are not monitored by direct measurements. The modeled and observed annual precipitation trends have been quantitatively compared to measure their agreement: bias is $-9.9 \mathrm{~mm}$, rmse is $23.4 \mathrm{~mm}$, and the spatial correlation is 0.66 . These comparisons show that the spatial distribution of simulated annual precipitation trend is reasonable but with model values that are slightly larger than observed. The model results during winter are similar to the annual results and agree closely with those obtained from high-elevation ice core measurements (Tables 2 and 3). This means that the model can

TABLE 3. Linear trend of simulated precipitation and observed accumulation at the T12e and B16d sites from 1992 to 2000 in winter $\left(\mathrm{mm} \mathrm{yr}^{-1}\right)$.

\begin{tabular}{lcc}
\hline \hline & $\mathrm{T} 12 \mathrm{e}$ & $\mathrm{B} 16 \mathrm{~d}$ \\
\hline Observed accumulation & $-110\left(\mathrm{R}^{2}=0.50\right)$ & $-60\left(\mathrm{R}^{2}=0.24\right)$ \\
Simulated precipitation & $-70\left(\mathrm{R}^{2}=0.62\right)$ & $-70\left(\mathrm{R}^{2}=0.63\right)$ \\
\hline
\end{tabular}

well simulate the annual precipitation trends for all of Iceland.

From central to southern Iceland, and over the sea to the east and west of Iceland, there is a major negative precipitation trend from 1991 to 2000 (Fig. 14). The large negative trend area is also found in model domain 2 and from the ECMWF TOGA precipitation (not shown); this demonstrates that the precipitation de-
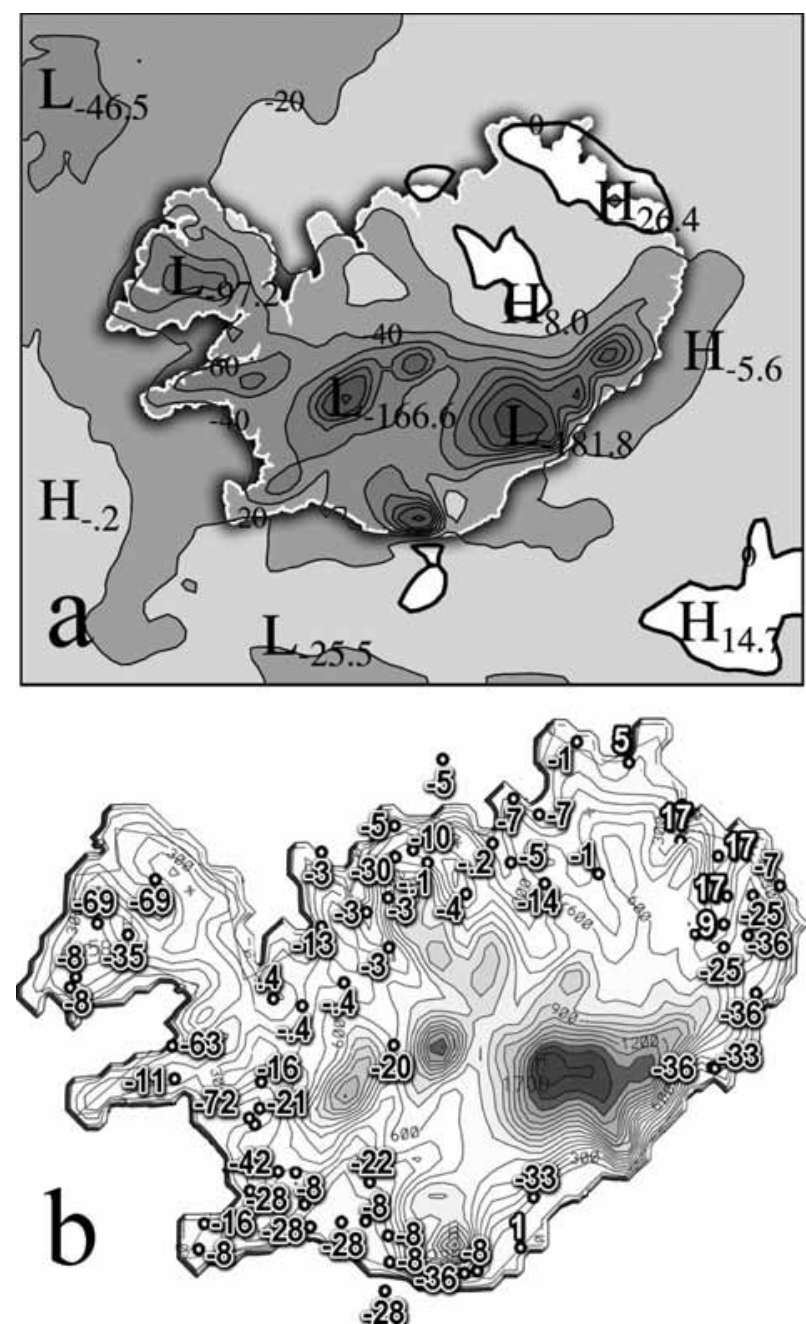

FIG. 14. (a) Annual precipitation trend in Iceland simulated by Polar MM5 from 1991 to $2000\left(\mathrm{~mm} \mathrm{yr}^{-1}\right)$. (b) Annual observation precipitation trend $\left(\mathrm{mm} \mathrm{yr}^{-1}\right)$ in Iceland for 1991-2000. Positive trends are highlighted. 

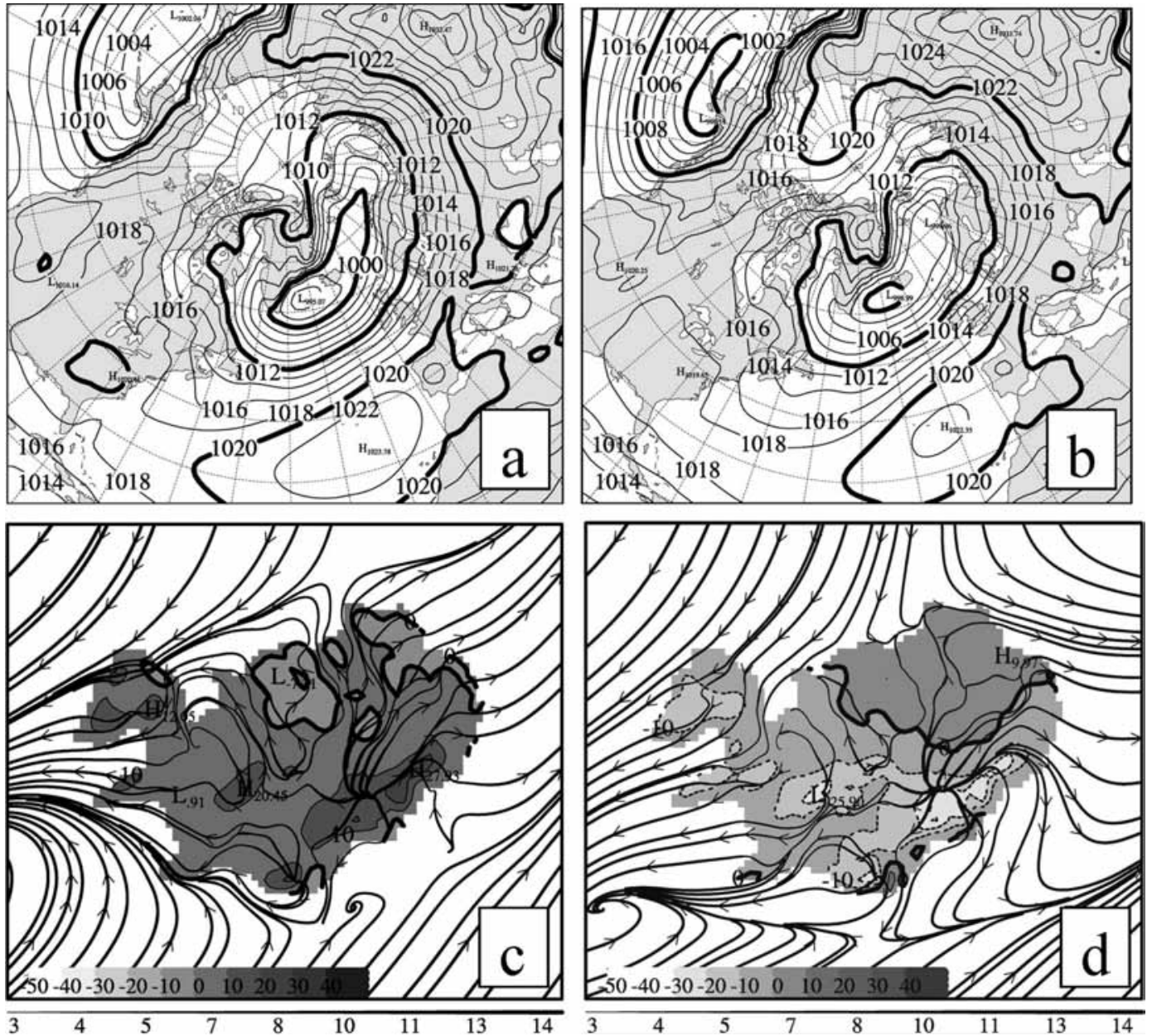

FIG. 15. The monthly mean sea level pressure in the winter half year (ONDJFM) (a) 1992-94, (b) 1996-98; contour interval is $2 \mathrm{hPa}$ and 1000-, 1010-, and 1020-hPa isobars are bold. The simulated monthly mean 10- $\mathrm{m}$ wind field and precipitation anomaly in the winter half year for (c) 1992-94 and (d) 1996-98. Width of streamline is proportional to wind speed with the scale shown beneath each streamline plot. Contour interval is $10 \mathrm{~mm}$ for precipitation, and negative contours are dashed.

crease is a large-scale climate feature that should be investigated.

\section{e. The relationship between circulation and precipitation}

The ECMWF 40-yr Re-Analysis (ERA-40; more information available online at $\mathrm{http} / / \mathrm{www} . e c m w f . i n t /)$ sea level pressure was used to investigate the relationship between the large-scale circulation and precipitation from 1991 to 2000. Figure 15 shows the monthly mean sea level pressure in the winter half year (ONDJFM) during 1992-94 (a high precipitation period with an NAO index of +1.0) and 1996-98 (a low precipitation period with an NAO index of -0.7 ; see Fig. 13), and the simulated monthly mean $10-\mathrm{m}$ winds and precipitation anomaly. It is can be seen that the Icelandic low during
1992-94 is stronger than during 1996-98 and the center of the Icelandic low is located to the southwest of Iceland. The Greenland high and associated northerly winds are weaker during 1992-94 and most of Iceland is controlled by southwesterly winds. The southwest nearsurface wind flows upslope over the southwest part of Iceland and results in the precipitation increase in this region. During 1996-98, the Icelandic low is weaker and shifted $4^{\circ} \sim 5^{\circ}$ toward the east and the Greenland high is stronger. Iceland was controlled by northeast winds and precipitation decreased over most of Iceland, except for the northeast region where there was an increase. The simulated mean precipitation difference between 199698 and 1992-94 in the winter half year (not shown) has a very similar pattern to the precipitation trend for 1991-2000 shown in Fig. 14a, thus confirming that the analysis in Fig. 15 represents the entire decade. The 
analysis reflects changes in the NAO modulation of regional climate. Both large-scale sea level pressure patterns are similar to the NAO positive phase, but the precipitation is different. Here the eastward shifting and weakening of the Icelandic low in 1996-98 coincides with negative NAO values in contrast to westward shifting and weakening earlier in the 1990s. Both patterns allow northeast winds associated with the Greenland high to dominate the atmospheric circulation over Iceland. Drinkwater (2004) found that the NAO index in the 1990s was the highest in the past 11 decades and there has been a general increase from the minimum of the 1960s. The early years of the 1990s were generally characterized by high NAO indices. In 1996, the NAO index experienced its largest annual decline in the over 100 -yr record, but during the remaining years of the 1990 s, the NAO rose to values that even exceeded those of the early years of the 1990s. A significant eastward shift of the Icelandic low occurred after 1995, consistent with Fig. 15. It can be summarized that the positions and intensities of the Icelandic low and Greenland high determine the precipitation distribution and change over Iceland.

\section{Conclusions}

High-resolution regional climate simulations over Iceland from 1991 to 2000 have been performed using Polar MM5 with three nested domains and shortduration integrations. The verification indicates that Polar MM5 accurately simulated the mesoscale and large-scale near-surface atmospheric circulations over Iceland on monthly time scales, thus the high-resolution regional climate in a limited area can be reasonably reconstructed using a limited-area model with reasonable physical parameterizations, and high-resolution topography and land use.

The simulation results are used to analyze the nearsurface wind, temperature, dewpoint, and precipitation climate over Iceland from 1991 to 2000. Katabatic winds are found to be one of the important climatic features in winter; the Iceland winds resemble a miniaturized version of those in Antarctica (cf. Parish and Bromwich 1991). The land-sea breeze is clearly evident in summer except over the Vatnajökull ice cap where downslope winds persist.

During January the 2-m temperature has a strong horizontal gradient along the southern coast, and a weaker gradient along the northern coast. As a result of the small diurnal variation, this temperature pattern is sustained all winter, and is generated by the winter katabatic winds. The daily range of near-surface air temperature is prominent in July over land, which forces the land-sea breeze in summer.
The time-averaged mesoscale precipitation distribution over Iceland is reasonably simulated by Polar MM5. Consistent with the cyclonic forcing changes, the winter amounts are much larger than those during the summer. The spatial distribution is maintained in each season, reflecting the dominant control of orography. The precipitation is larger than average for the positive NAO phase especially over southeast Iceland, whereas for the negative NAO phase the precipitation is reduced, particularly in western and southern Iceland. The relationship applies throughout the year. By contrast, surface temperature and moisture are lower than normal during the winter half year for the NAO positive phase and higher than normal during the summer half year, a consequence of the seasonally varying atmospheric advection. Examination of 40-yr ECMWF Re-Analysis (ERA-40) fields reveals that these results for 1991-2000 are very similar to those for 1958-2001 (not shown).

The precipitation decreases strongly over all of Iceland from 1991 to 2000 except for the eastern and northeastern parts where the precipitation slightly increases. During the winter half year, the Icelandic low became weaker and its center is shifted toward the east, and the Greenland high is intensified. This shift reflects a modification of the NAO modulation of regional climate. This altered circulation resulted in stronger north and east winds, and weaker south winds; as a result precipitation decreased in south and southwest Iceland, and increased in the east.

The 10-yr simulation results indicate that Polar MM5 is a powerful tool for mesoscale regional climate studies in the data-sparse high latitudes. The high-resolution regional climate simulation can be further improved by using three-dimensional variational assimilation in conjunction with Polar MM5 to assimilate observational data over steep topography and by using a land surface model over Iceland.

Acknowledgments. This research was sponsored by NASA Grants NAG5-12407 and NAG5-745889. We greatly appreciate the assistance of $\mathrm{H}$. Gudmundsson in finalizing this manuscript.

\section{REFERENCES}

Björnsson, H., F. Pálsson, M. T. Guðmundsson, and H. H. Haraldsson, 1998: Mass balance of western and northern Vatnajökull, Iceland, 1991-1995. Jökull, 45, 35-58.

Box, J. E., D. H. Bromwich, and L.-S. Bai, 2004: Greenland ice sheet surface mass balance 1991-2000: Application of Polar MM5 mesoscale model and in situ data. J. Geophys. Res., 109, D16105, doi:10.1029/2003JD004451.

Bromwich, D. H., J. J. Cassano, T. Klein, G. Heinemann, K. M. Hines, K. Steffen, and J. E. Box, 2001: Mesoscale modeling of 
katabatic winds over Greenland with the Polar MM5. Mon. Wea. Rev., 129, 2290-2309.

Cassano, J. J., J. E. Box, D. H. Bromwich, L. Li, and K. Steffen, 2001: Evaluation of Polar MM5 simulations of Greenland's atmospheric circulation. J. Geophys. Res., 106, 33 867-33 890.

Chu, P. C., and C. W. Fan, 1997: Sixth-order difference scheme for sigma coordinate ocean models. J. Phys. Oceanogr., 27, 20642071.

Drinkwater, K. F., 2004: Atmospheric and sea-ice conditions in the Northwest Atlantic during the decade, 1991-2000. J. Northwest Atl. Fish. Sci., 34, 1-11.

Einarsson, M. A., 1984: Climate of Iceland. World Survey of Climatology, H. van Loon, Ed., Vol. 15, Climate of the Oceans, Elsevier, 673-697.

Frei, C., and C. Schaer, 1998: A precipitation climatology of the Alps from high-resolution rain-gauge observations. Int. J. Climatol., 18, 873-900.

Grell, G. L., J. Dudhia, and D. R. Stauffer, 1994: A description of the fifth-generation Penn State/NCAR Mesoscale Model (MM5). NCAR Tech. Note NCAR/TN-398+STR, 122 pp.

Kaltenböck, R., and F. Obleitner, 1999: On a low cloud phenomenon at the Breidamerkurjökull glacier, Iceland. Bound.Layer Meteor., 92, 145-162.

Moss, M. E., C. P. Pearson, and A. I. McKerchar, 1994: The SOI as a predictor of the probability of low streamflows in New Zealand. Water Resour. Res., 30, 2717-2727.

Oerlemans, J., H. Björnsson, M. Kuhn, F. Obleitner, F. Palsson, C. J. P. P. Smeets, H. F. Vugts, and J. De Wolde, 1999: Glaciometeorological investigations on Vatnajökull, Iceland, summer 1996: An overview. Bound.-Layer Meteor., 92, 3-26.

Pan, Z., E. Takle, W. Gutowski, and R. Turner, 1999: Long simulation of regional climate as a sequence of short segments. Mon. Wea. Rev., 127, 308-321.

Parish, T. R., and D. H. Bromwich, 1991: Continental-scale simulation of the Antarctic katabatic wind regime. J. Climate, 4, 135-146.

Qian, J.-H., A. Seth, and S. Zebiak, 2003: Reinitialized versus continuous simulations for regional climate downscaling. Mon. Wea. Rev., 131, 2857-2874.

Reisner, J., R. M. Rasmussen, and R. T. Bruintjes, 1998: Explicit forecasting of supercooled liquid water in winter storms using the MM5 mesoscale model. Quart. J. Roy. Meteor. Soc., 124, 1071-1107.

Rinke, A., and K. Dethloff, 2000: On the sensitivity of a regional Arctic climate model to initial and boundary conditions. Climate Res., 14, 101-113.

_ - _ A. Spekat, W. Enke, and J. H. Christensen, 1999a: High resolution climate simulations over the Arctic. Polar Res., 18 (2), 1-9.

- - , and J. H. Christensen, 1999b: Arctic winter climate and its interannual variations simulated by a regional climate model. J. Geophys. Res., 104, 19 027-19 038.

Rogers, J. C., 1984: The association between the North Atlantic Oscillation and the Southern Oscillation in the Northern Hemisphere. Mon. Wea. Rev., 112, 1999-2015.

Rögnvaldsson, O., and H. Ólafsson, 2002: Downscaling experiments with the MM5 model: Determining an optimal configuration for climatological downscaling studies of precipitation in Iceland. Icelandic Meteorological Office, $21 \mathrm{pp}$. [Available online at http://www.vedur.is/ haraldur/urkoma. pdf.]

_ P. Crochet, and H. Ólafsson, 2004: Estimation of precipitation in complex terrain. Preprints, 10th Conf. on Mesoscale Processes, Portland, OR, Amer. Meteor. Soc., CD-ROM, P1.19.

von Storch, H., H. Langenberg, and F. Feser, 2000: A spectral nudging technique for dynamical downscaling purposes. Mon. Wea. Rev., 128, 3664-3673.

Wei, H., D. H. Bromwich, L. S. Bai, Y.-H. Kuo, and T. K. Wee, 2002: A case study of the impact of the upper boundary condition in Polar MM5 simulations over Antarctica. Preprints, 12th PSU/NCAR Mesoscale Model Users' Workshop, Boulder, CO, PSU-NCAR, CD-ROM. [Available online at http:// www.mmm.ucar.edu/mm5/workshop/ws02/Wei.pdf.] 